\title{
Same-Race Role-models and Self-Efficacy among African American College Students
}

\author{
Rueben Brock
}

Follow this and additional works at: https://researchrepository.wvu.edu/etd

\section{Recommended Citation}

Brock, Rueben, "Same-Race Role-models and Self-Efficacy among African American College Students" (2015). Graduate Theses, Dissertations, and Problem Reports. 5259.

https://researchrepository.wvu.edu/etd/5259

This Dissertation is protected by copyright and/or related rights. It has been brought to you by the The Research Repository @ WVU with permission from the rights-holder(s). You are free to use this Dissertation in any way that is permitted by the copyright and related rights legislation that applies to your use. For other uses you must obtain permission from the rights-holder(s) directly, unless additional rights are indicated by a Creative Commons license in the record and/ or on the work itself. This Dissertation has been accepted for inclusion in WVU Graduate Theses, Dissertations, and Problem Reports collection by an authorized administrator of The Research Repository @ WVU.

For more information, please contact researchrepository@mail.wvu.edu. 
Same-Race Role-models and Self-Efficacy among African American College Students

\author{
Rueben Brock \\ Dissertation submitted to the \\ College of Education and Human Services \\ at West Virginia University \\ in partial fulfillment of the requirements for the degree of
}

\author{
Doctor of Philosophy \\ In \\ Counseling Psychology \\ Jeffrey Daniels, PhD, Chair \\ Jennifer Taylor, $\mathrm{PhD}$ \\ Reagan Curtis, $\mathrm{PhD}$ \\ George Mamboleo, PhD \\ Taunya Tinsley, $\mathrm{PhD}$
}

Morgantown, West Virginia

2015

Keywords: Role-model; self-efficacy; African American; academic; career

Copyright 2015 Rueben Brock 


\begin{abstract}
Same-Race Role-models and Self-Efficacy among African American College Students
\end{abstract}

Rueben Brock

Social Cognitive Career Theory (SCCT; Lent \& Brown, 1996) offers an understanding of career interest, goals, and performance. It is based, in large part, on the social cognitive construct of self-efficacy (Bandura, 1986). The theory offers a framework for the interactive influence that self-efficacy, outcomes expectations, and personal goals have upon each other in the formation of a person's career aspirations. Within SCCT and the Social Learning Theory that it is based on, there is the presumption that modeling is a key component of learning (Bandura, 1986). The purpose of this study was to explore the impact that same-race role-models may have on the career and academic self-efficacy of African American college students. Results of a regression analysis indicated no significant relationship between the number of role-models on the career and academic self-efficacy of the participants. These results call into question the impact of rolemodeling programs that use race matching as a method of increasing African American student success. At least with respect to self-efficacy beliefs, the current study indicates that an increase in same race role-models is not impactful for students. 


\section{Table of Contents}

Dissertation Abstract $\quad$ ii

Chapter 1: Introduction/Review of Literature 1

$\begin{array}{ll}\text { Social Cognitive Career Theory and Minority Students } & 7\end{array}$

$\begin{array}{ll}\text { Social Cognitive Career Theory and Gender } & 21\end{array}$

$\begin{array}{ll}\text { Self-Efficacy and Achievement } & 23\end{array}$

$\begin{array}{ll}\text { Improving Self-Efficacy } & 30\end{array}$

Chapter 2: Methods

$\begin{array}{ll}\text { Research Question } & 59\end{array}$

$\begin{array}{lr}\text { Design } & 59\end{array}$

$\begin{array}{ll}\text { Participants } & 60\end{array}$

$\begin{array}{ll}\text { Variables and Measures } & 61\end{array}$

$\begin{array}{ll}\text { Procedures } & 64\end{array}$

$\begin{array}{ll}\text { Analysis } & 64\end{array}$

$\begin{array}{ll}\text { Chapter 3: Results } & 66\end{array}$

$\begin{array}{ll}\text { Descriptive Statistics } & 66\end{array}$

$\begin{array}{ll}\text { Analysis of Hypotheses } & 67\end{array}$

$\begin{array}{ll}\text { Chapter 4: Discussion } & 71\end{array}$

$\begin{array}{ll}\text { Limitations } & 74\end{array}$

$\begin{array}{ll}\text { Strengths } & 77\end{array}$

$\begin{array}{ll}\text { Future Directions } & 78\end{array}$

$\begin{array}{ll}\text { Contributions to the Field } & 79\end{array}$ 
$\begin{array}{ll}\text { Conclusion } & 81\end{array}$

$\begin{array}{ll}\text { References } & 82\end{array}$

$\begin{array}{ll}\text { Appendixes } & 94\end{array}$ 


\section{Table of Figures}

1.1. Triadic Reciprocity 4

1.2. Social Cognitive Career Theory 5 


\section{Table of Tables}

Table 1. Regression Analysis Predicting Self-Efficacy 68

Table 2. Unique Predictive Value of Teacher Role-models 70 


\section{Chapter 1: Introduction}

Much has been written over the past several decades about the academic performance of minority students in higher education. Researchers examining the underrepresentation of many minority populations in various careers and the disparity in performance between some minority groups and their majority counterparts have been inspired to investigate the possible causes of this phenomenon in American education systems (Solberg, O'Brien, Villareal, Kennel, \& Davis, 1993). In doing so, these researchers have found self-efficacy to be a consistent predictor of career goals and student performance among minorities (Lease, 2006; Witherspoon \& Speight, 2009).

Social Cognitive Career Theory (SCCT; Lent \& Brown, 1996) was developed to offer an understanding of career interests, goals, and performance. It is based, in large part, on the social cognitive construct of self-efficacy (Bandura, 1986). The theory contains a framework for the interactions of self-efficacy, outcome expectations, and personal goals in the formation of a person's career aspirations. Within SCCT, and the Social Learning Theory that it is based on, there is a presumption that modeling is a key component of learning (Bandura, 1986), and by extension, an important component of self-efficacy (Lent \& Brown, 1996).

Modeling, within the context of Bandura's Social Learning Theory, is the exchange or acquisition of knowledge through observation and imitation (1986). Bandura suggested that behavior is shaped through environmental exposure to and interaction with these models. This concept has been researched and applied within the context of everything from language (Vogt, 2010) to mathematics (Rowan-Kenyon, Swan, \& Creager, 2012).

Over the past twenty years, researchers have attempted to understand the impact that modeling has on career and educational outcomes. Many have suggested that exposure to 
models of behavior plays an important role in improving the performance of minority students (Credle \& Dean, 1991; Henry, Bardo, \& Henry, 1992). Perhaps inspired by this research, programs have been created in order to test the effectiveness of role-modeling as an intervention for minority students (Linnehan, 2001; Santos \& Reigadas, 2000; Thile, 1995). Although these programs have yielded promising results with respect to establishing the positive influence that modeling may have on academic performance, their design fails to specifically address one of the variables that has been found most predictive of career and academic outcomes: the races of the models and the students. With this gap in the literature in mind, this study is designed to examine the impact of exposure to same-race models on career and academic self-efficacy. Specifically, I intend to examine the impact of these exposures on the career and academic selfefficacy of African American college students.

\section{Social Cognitive Career Theory}

Several prominent theories within psychology and counseling have been developed to address issues related to career paths. Super's (1953) theory of career development was offered as a tool for understanding the stages that a person goes through in the development of their career. The theory provides insight into the common concerns and issues that arise at particular times in a person's career. Holland (1959) developed a theory of career choice that helped bring light to the intersection between career choice and career satisfaction, suggesting that a person will flourish in a career that matches their personality type. Wingfield and Eccles (2002) created a theory that addresses the intersection of motivation, beliefs, values, and goals. Although Winfield and Eccles' work focused primarily on academic achievement, their work provides strong insights into what factors influence a student's goal decision-making post-school. 
Like the work of Wingfield and Eccles, Social Cognitive Career Theory (Lent, Brown, \& Hackett, 1994; SCCT) is influenced by Bandura's work regarding social learning and selfefficacy. Unlike previously mentioned theories, however, SCCT takes a much closer look at the impact of social learning on career choice. For this reason, SCCT is perhaps the theory best used to explore the current question.

Social Cognitive Career Theory was developed as a means of unifying existing theories and ideas about career development (Lent et al., 1994). Through the theory, Lent and colleagues addressed shortcomings of previous theories, which, according to the authors, did not address the dynamic nature of human decision making with respect to career goals and behaviors. At the core of this theory is Social Learning Theory and the concept of self-referent thinking as a guide for motivation and behavior (Bandura, 1986). While this approach does recognize the importance of biology, development, affect, and other factors as important to the development of career paths, the developers of SCCT proposed that social cognitive theory includes a viable framework for the interactive nature that all of these factors play in guiding decision making (Lent et al., 1994).

An important and foundational concept in the establishment of SCCT is the idea of triadic reciprocity (Bandura, 1986). Triadic reciprocity is a recognition of the bidirectional relationship that exists among (a) personal attributes, such as physical, cognitive, and affective traits; (b) external environmental factors; and (c) overt behavior (see Figure 1.1; Pajares, 2002). While the proponents of earlier theories recognized the influence that personal attributes and environment had on behavior, the relationship they posited was less reciprocal, assuming that behavior is a byproduct of the relationship between the previous factors. Albert Bandura, however, posited 
that people's behaviors have a direct influence on their situations, which, in turn, have an impact on their thoughts and environment (Lent et al., 1994).

\section{Figure 1.1. Triadic Reciprocity}

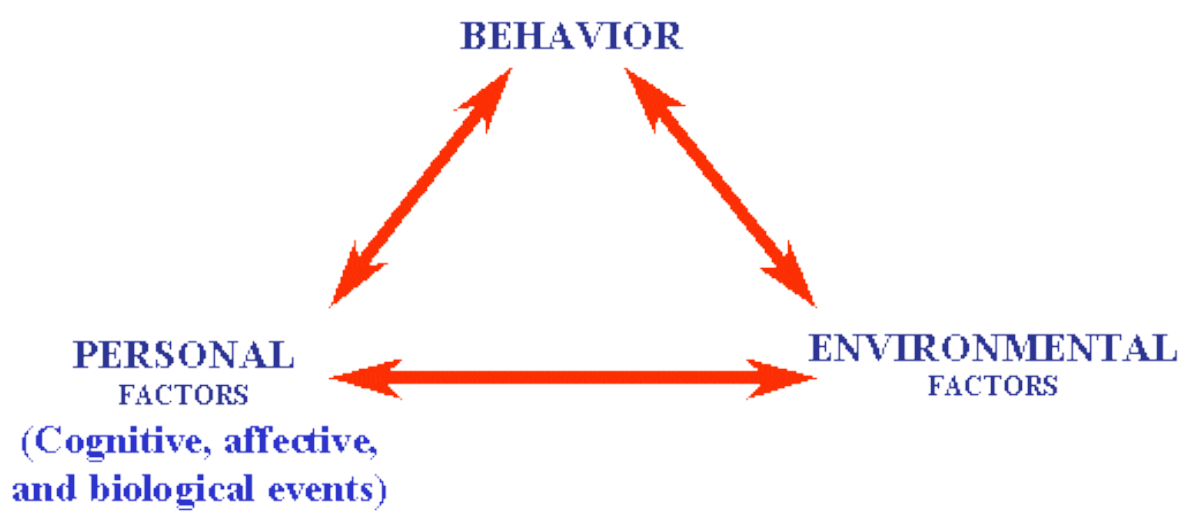

Another concept in SCCT is that three major cognitive factors shape the way people make career decisions (Lent et al., 1994). These factors-personal goals, outcome expectations, and self-efficacy - interact to influence psychological functioning. These factors and the relationships they have with one another were first introduced by Albert Bandura (1986). This model was incorporated in SCCT as a theory of the formulation of ideas and behaviors that shape career paths (Lent \& Brown, 1996). The model serves as a predictor of a person's career choices (see Figure 1.2).

Personal goals can be defined as one's intention to engage in an activity or to produce an outcome (Bandura, 1986). Goals are an important element in the shaping of career choices. When people set personal goals, they create for themselves the structure by which they guide and sustain efforts over time (Lent \& Brown, 1996). According to SCCT, people's personal goals are heavily influenced by outcome expectations and self-efficacy. 
Bandura (1986) described outcome expectations as the beliefs a person has about the outcome of an action. For example, one might believe that becoming a professional athlete (action) would lead to a substantial income (outcome). According to SCCT, these beliefs play an important role in forming personal goals. However, self-efficacy is presumed to have an even greater effect on these goals. In the previous example, a young man might believe that a life as a professional athlete would lead to wealth. If, however, he also believes that he does not possess the skills to attain that goal, he is unlikely to set that goal and will ultimately choose another career path.

\section{Figure 1.2 Social Cognitive Career Theory}

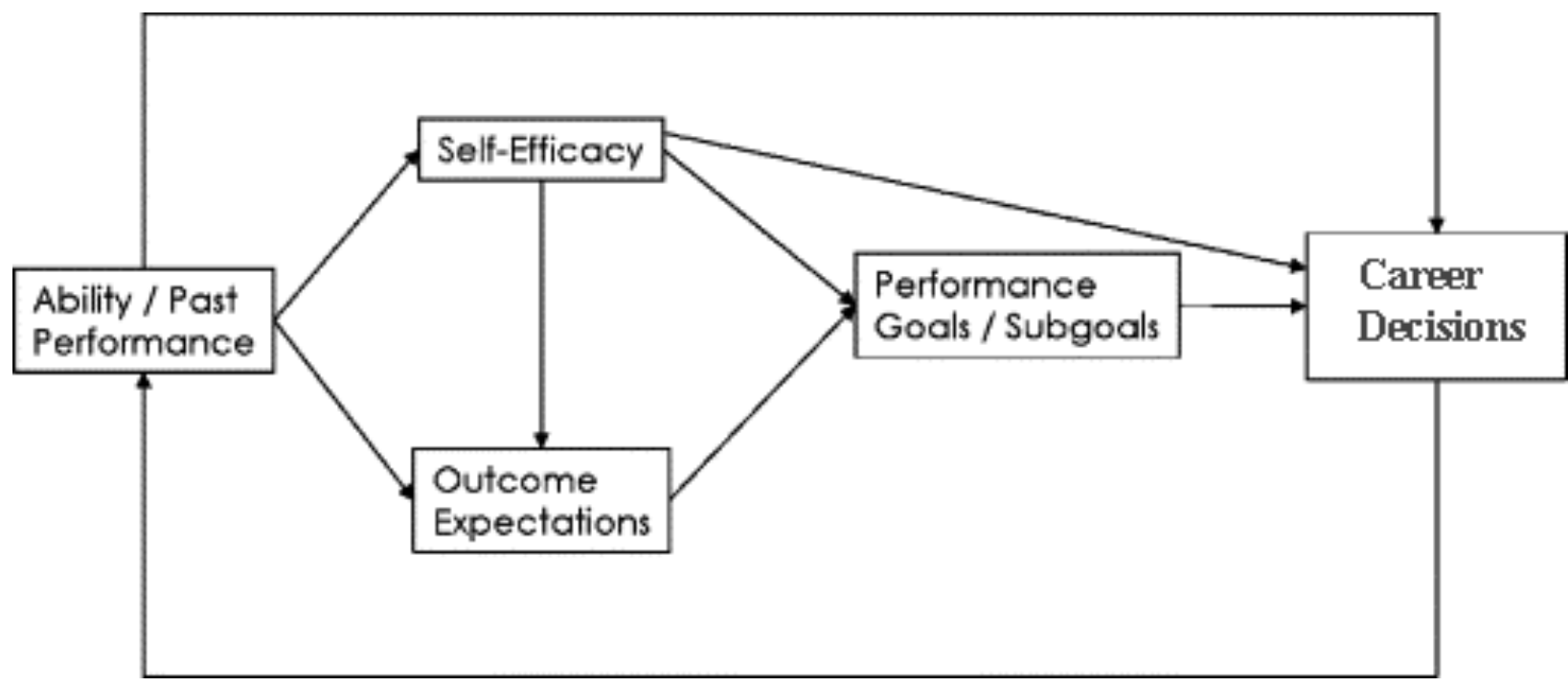

Self-efficacy is defined as "people's judgments of their capabilities to organize and execute courses of action required to attain designated types of performances" (Bandura, 1986, p. 391). Bandura suggested that self-efficacy had the most significant influence on personal goals. This concept is perhaps the most central theme of SCCT. A person's belief about his or her ability to attain a goal is a major factor in the choosing of or foreclosure on that goal. Therefore, 
much of the intervention process in SCCT involves evaluating the accuracy of self-efficacy beliefs and outcomes expectations.

Self-efficacy beliefs are shaped and modified by four sources: (1) personal performance accomplishments, (2) vicarious learning, (3) social persuasion, and (4) physiological states (Bandura, 1986). Of the four, personal performance accomplishments are believed to have the greatest influence on self-efficacy. The experience of success or failure at a given task or behavior has a profound effect on a person's thoughts about that behavior as a plausible goal for the future. Success in a career or academic domain will increase a person's self-efficacy in that domain, while failure will have the opposite effect of decreasing the person's self-efficacy in the domain. This phenomenon is primarily an internal one, as it involves a person's appraisal and evaluation of his or her own experience within a particular domain.

Vicarious learning and social persuasion, however, are primarily environmental phenomena. Vicarious learning is the observation of significant figures within one's life. Especially significant in adolescence and young adulthood, vicarious learning can come from viewing family members, caregivers, and community members (Hackett \& Byars, 1996). As adolescents view those around them, they internalize powerful messages about their own abilities to perform tasks.

Social persuasion is the feedback that a person gets from performing a task or displaying a behavior. Very similar to vicarious learning, this concept is the internalization of messages from figures within a person's world. These messages, however, are not implied. While vicarious learning involves the covert messages that one receives through interpretation of others' actions, social persuasion is the actual verbal encouragement or discouragement received for one's behavior. Physiological states refer to the states of arousal that a person experiences. 
Anxiety, in particular, can have an impact on self-efficacy. Increased anxiety in connection with a behavior or task is correlated with lower self-efficacy beliefs, and decreased anxiety tends to be related to stronger self-efficacy beliefs (Bandura, Reese, \& Adams, 1982).

According to SCCT, learning experiences are defined as the verbal encouragements, vicarious learning, physiological arousal, and performance accomplishments that work together to make up self-efficacy (Lent et al., 1994). Environmental factors like family, friends, teachers, and a person's community play a major role in shaping learning experiences and, therefore, selfefficacy. Growing up in a nurturing and positive environment is likely to provide an adolescent with an abundance of learning experiences that enhance self-efficacy. Conversely, growing up with a lack of social and financial support can lead to lower self-efficacy in one's ability to pursue higher education and career goals (Ali \& Saunders, 2009).

Considerable study has been performed on SCCT over the past two decades. Most of the research on SCCT has been focused on the impact that self-efficacy has on career outcomes. The results of empirical research confirm a causal link between self-efficacy beliefs and a person's career path (Bandura et al., 2001). Although Lent et al. (1994) suggested that racial development and racial socialization could have significant impact on the career development of minorities, there are relatively few studies that test these specific variables. The limited research does, however, show support for the impact of cultural variables on career decisions (Flores \& O’Brien, 2002; Gloria \& Hird, 1999; Tang, Fouad, \& Smith, 1999).

\section{SCCT and Minority Students}

Social Cognitive Career Theory has been used as a means for understanding and predicting career paths among minority students. A small number of the researchers of SCCT have focused on Mexican American students. This population was used in the creation of one of 
the few scales developed to measure college self-efficacy (Solberg, Villarel, \& Kennel, 1993). The authors validated the College Self-Efficacy Inventory using 164 Mexican American and Latino American college students by administering the 20 -item instrument along with the Brief Symptoms Inventory, a multicultural stress inventory, a measure of acculturation, and two social support measures. The researchers used their findings to establish the Course Efficacy, Roommate Efficacy, and Social Efficacy subscales within the College Self-Efficacy scale. Internal consistency reliability for the instrument was established by calculating Cronbach's alpha (.93). Convergent and discriminant validity were established by submitting scores of the scale, along with scores from other measures of self-efficacy, acculturation, and social support, to a principle component analysis with varimax rotation. The subscales of the College SelfEfficacy Inventory, along with the additional scales used in the study, were analyzed, and the results indicated that the subscales of the instrument were related to other indexes of adjustment and discriminate from non-adjustment constructs. Results of a multivariate analysis of variance (MANOVA) also revealed no main effect of acculturation on efficacy. Multivariate and corresponding univariate analyses of variance were conducted to test the interaction and influence of gender, class, acculturation, and class standing on self-efficacy. One univariate effect was significant for the interaction among social self-efficacy, gender, and acculturation. However, because the MANOVA was not statistically significant, the authors noted that the interaction effect was likely to be spurious (Solberg et al., 1993).

Flores and O'Brien (2002) used SCCT as a model for the prediction of career aspirations among Mexican American adolescent women. Participants for this study were selected from Mexican American female high school seniors in a mid-sized Texas town that borders Mexico. A total of 931 surveys were completed, of which 381 were included in the study. Only female 
seniors who self-identified as Mexican American were used in the study. Authors administered instruments measuring constructs related to SCCT, including each participant's acculturation level, feminist attitudes, mother's level of education, parental support, non-traditional career selfefficacy, perceived occupational barriers, and career choice prestige and traditionality. The authors also gathered demographic information. These variables were measured to test a hypothesized model for predicting career choice prestige among Mexican American adolescent females. The model was based on a hypothesized path from acculturation levels, feminist attitudes, mothers' education level, and mothers' occupational traditionality to nontraditional career self-efficacy; nontraditional career self-efficacy to nontraditional career interests; and nontraditional career self-efficacy, nontraditional career interests, parental support, and perceived future barriers to career choice prestige.

Chi-square and other tests of goodness of fit found that the data fit the model poorly, thereby rejecting the authors' model (Flores \& O'Brien, 2002). However, after modifications to the model were made, results emerged that were consistent with SCCT. Consistent with the theory, nontraditional career self-efficacy was found to be predictive of nontraditional career interests. Nontraditional career self-efficacy also had a positive effect on career choice prestige and a negative effect on career choice traditionality.

Flores, Navarro, and DeWitz (2008) also examined SCCT concepts as they relate to Mexican American students. For this study, 89 English-speaking high school seniors who selfidentified as Mexican American (males = 27; females =62) were assessed to evaluate differences in self-reported educational aspirations and educational expectations. These differences were then tested against a framework of SCCT and prior research regarding Mexican American students. The authors hypothesized that Anglo-oriented acculturation, college self- 
efficacy, and college outcome expectations would be positively associated with high educational goal aspirations and expectations.

Students were assessed on college self-efficacy, acculturation, college outcome expectations, and educational goal expectations and aspirations (Flores, Navarro, \& DeWitz, 2008). Demographic information was also collected. After a MANOVA was performed to rule out differences in gender and generation level, a paired-samples $t$-test was conducted to determine if there were significant differences between educational aspirations and expectations for this sample. The result suggested that Mexican American high school students had higher educational aspirations $(M=7.43, \mathrm{SD} 1.78)$ than they had educational expectations $(M=6.63$, SD 2.13). Further analysis of the variables indicated that, contrary to the hypothesis, college self-efficacy was not related to college outcome expectations. In fact, of the variables studied, only Anglo-orientation was related to either educational factor, being found to have a positive effect on educational aspirations $p<.01, \eta=.11$ (when $\eta$ represents the univariate effect size) and educational expectations, $p<.01, \eta=.10$.

It is important to note that, according to the study's results, Mexican American students have a discrepancy between that which they aspire to do and that which they believe they will achieve. The researchers' findings also illustrate that this discrepancy exists before these students ever experience the difficulties of higher education. The study's design, however, does not address how this discrepancy emerges (Flores et al., 2008).

Mexican American students are not the only students who have been the subject of research within SCCT. African American students have also received a considerable amount of attention from researchers within social cognitive studies. It would seem that, with an understanding of how social learning shapes self-efficacy, African American adolescents have a 
unique challenge with respect to forming a healthy and positive set of self-efficacy beliefs. At the time when adolescents are most impressionable in the formation of self-efficacy beliefs (Lent \& Brown, 1996), African American adolescents also have to learn to navigate the racism, discrimination, and prejudice that they will inevitably face in school and in their communities. All four information sources that shape self-efficacy can be impacted by membership in a racial group with such biases and stigmas attributed to it. Greene (1990), for example, posited that African American women often face differential feedback applied to their performances. Greene asserted that behavior that might be rewarded by a teacher when displayed by other students, such as persistently attempting to answer questions, is often ignored or discouraged in African American students. Based on these findings, it can be suggested that it would be important to address the impact that race has on career self-efficacy of African American students.

As is often the case within social cognitive literature, women and men are studied separately when unpacking issues of self-efficacy (Flores \& O'Brien, 2002; Hackett \& Betz, 1981; Hackett \& Byars, 1996). Hackett and Byars (1996), in an exploratory paper addressing the lack of understanding about issues of ethnicity and how they impact career self-efficacy, suggested that all four sources of self-efficacy are uniquely impacted in African American women. Performance accomplishments, they noted, are one in which African American women have a distinct disadvantage. Differential treatment with respect to wages, promotions, and job placement within the U.S. workforce are prime societal examples of the difficulties African American women can face in assessing their own performance accomplishments. Ogbu (1991) referred to this phenomenon as the "attitude achievement paradox," pointing out that African Americans can develop negative outcome expectations as they realize that their belief in and 
closely held values of things like educational attainment are not matched by actual achievement in those areas.

Hackett and Byars (1996) also pointed out that African American women may actually have a relative advantage over their non-African American counterparts with respect to vicarious learning, which is a key component to any role-modeling argument. Due to the fact that African American women tend to display very nontraditional roles (Synder \& Dillow, 2010) with respect to career attainment, African American girls may not be as burdened by the stigma attached to high-achieving, independent women. African American women have a history and tradition of strength and independence that is undoubtedly passed on to girls at an early age through exposure to caregivers and family members who embody these traits. This may help explain how the discrepancy in academic achievement among African American men and women is more pronounced than in other ethnic groups. While Asian American, Latina, Native American, and Caucasian women all outperform men of the same race in terms of degree attainment, none of these groups do so at the rate of African American women (Synder \& Dillow, 2010).

Still, social, academic, and professional patterns also play a role in the vicarious learning experience of African American adolescents. It is not uncommon for an African American student to go through his or her entire elementary and secondary education without significant exposure to same-race role-models in academic and professional positions. This lack of exposure can negatively affect an adolescent's likelihood of choosing career paths that would appear, in these instances, to be outside of the realm of possibility (Durodoye \& Bodley, 1997). Additionally, a mere lack of efficacy-building experiences, brought on by a negative social environment, can also have a negative effect (Lent \& Brown, 1996). These factors all contribute to the premature foreclosure of career goals in certain areas due to low self-efficacy beliefs. 
The physiological experience of discomfort in attempting to navigate the anxiety brought on by racism and sexism also has an impact on self-efficacy (Hackett \& Byars, 1996). African American students in elementary and junior high school experience increased distrust and paranoia on the part of Caucasians. This translates to emotional arousal, which impacts performance and goal-setting abilities.

Social persuasion, the final source of influence on self-efficacy, is susceptible to racial impact as well. African American adolescents, especially females, contend with conflicting messages from parents about academic achievement. While parents may send children hopeful messages about their academic abilities, they may also relay discouraging messages through their personal experiences of encountering differential treatment in career and academic environments. These messages of frustrations inadvertently conveyed by parents are likely to damage the self-efficacy beliefs of children and adolescents (Hackett \& Byars, 1996).

In addition to studies involving African American females, African American students, as a whole, have also been studied within the context of SCCT. Lease (2006) attempted to assess SCCT-related factors, including race salience, socioeconomic status (SES), self-efficacy, career barriers, and occupational interests, and the impact of these factors on career choices for future employment among African American high school students. Students were assessed for their tendencies toward jobs where African Americans are proportionately represented within the United States (greater than 13.5\%) and those where they are underrepresented (less than 5\%). Lease hypothesized that the students would have less efficacy for and interest in occupations where African Americans are underrepresented and would be less likely to see these occupations as viable career paths. She also hypothesized that racial centrality, education and career-related barriers, self-efficacy, and interest would be predictive of the range of representative and non- 
representative careers considered by the students. Lease further hypothesized that perceived barriers would be a moderating factor in the relationship between self-efficacy and career consideration for both representative and non-representative career paths (Lease, 2006).

In order to test these hypotheses, a series of inventories were administered to 166 African American high school juniors and seniors (males $=73$; females $=88$; not reported $=5$ ) from the mid-southern region of the United States. Students ranged in age from 15 years to 19 years, with a mean age of 16.9 years. The majority of students reported that their parents attained high school diplomas or less education. Of the 166 students, $40 \%$ aspired to a bachelor's degree or less, $29 \%$ aspired to a master's degree, and $27 \%$ aspired to a doctoral or professional degree (Lease, 2006).

Instruments that were administered included the Multidimensional Inventory of Black Identity, which measures African American identity as proposed by the multidimensional model (Sellers et al., 1997), and Perception of Barriers, which measures a person's perception of likely barriers to career and academic goals. Social Cognitive Predictors were assessed by dividing a set of occupations, based on the 2000 U.S. Census numbers, into two categories, representative and non-representative. Students were then asked to rate their level of confidence in their ability to follow these career paths. Basic demographic information, such as gender, age, race, grade level, and parental education level, was also gathered (Lease, 2006).

A one-way MANOVA was computed to assess gender differences with respect to SES and degree aspiration. This test found no significant differences. A second MANOVA did show that females were more likely to be interested in and consider African American-representative occupations than males (Wilks $\mathrm{F}=3.55, p<.01$ ). Dependent sample mean tests determined that, contrary to the hypothesis, there was not a significant difference in the number of representative 
and non-representative occupations considered by the students. Likewise, interest and selfefficacy were equal in representative and non-representative occupations. Examination of intercorrelations among factors revealed that occupational self-efficacy, perception of barriers, and interest were consistent predictors of career choice. When barriers to a career were perceived to be low, self-efficacy and interest, two major SCCT constructs, were highly predictive of choice. When barriers were perceived to be high, self-efficacy ceased to be a significant predictor of choice. Although the authors failed to point this out, this fact may also be explained in SCCT terms - perception of barriers could be reframed as negative outcome expectations, which is a central factor in SCCT. Nevertheless, the study lends credibility to the predictive ability of SCCT in African American students (Lease, 2006).

In a similar study, Witherspoon and Speight (2009) attempted to identify predictors of African American student interest in traditional and nontraditional occupations. They hypothesized that African self-consciousness and experiences of racism would both have a positive relationship with interest in traditional occupations. They also predicted that African self-consciousness, occupational self-efficacy, and experiences of racism would be strong predictors of occupational interests. It was additionally believed that African self-consciousness would contribute unique variance to the prediction of occupational interest. For this study, African self-consciousness was defined as an awareness of one's African identity and culture; recognition of African survival priorities and the necessity of Africentric institutions; participation in activities that promote African survival, liberation, and development; and recognition of and opposition to racial oppression.

To test these hypotheses, Witherspoon and Speight (2009) recruited 129 African Americans from predominantly Black colleges and universities (male $=30$; female $=99$ ). 
Students ranged in age from 16 to 70 years $(M=27, S D=10.12)$. Students were asked to complete instruments including Occupational Self-Efficacy, Occupational Interest Scale, African Self-Consciousness Scale, and Schedule of Racist Events.

A multivariate analysis of variance indicated main effect differences for African selfconsciousness and interest in traditional occupations. Gender was found to be significantly related to African self-consciousness, with men reporting significantly higher scores than women $(F=11.9, p<.01)$. Women were found to have significantly higher interest in traditional occupations $(F=9.4, p<.01)$. Contrary to the hypothesis, there was no relationship between African self-consciousness, which was defined as commitment to African American culture, and interest in traditional occupations. The authors also found no relationship between experiences of racism and interest in traditional occupations. The hypothesis that African self-consciousness, occupational self-efficacy, and experiences of racism would be predictive of occupational interests was partially supported. Occupational self-efficacy (for traditional and nontraditional occupations) and gender were significant predictors of interest in traditional occupations. African self-consciousness did not contribute any unique variance to the prediction of interest in traditional occupations and, thus, did not support the hypothesis. Only non-traditional selfefficacy was found to be a significant predictor of interest in non-traditional occupations, accounting for $25 \%$ of the variance in scores (Witherspoon \& Speight, 2009).

These results added valuable credibility to the predictive value of self-efficacy, suggesting that as self-efficacy increases, so does interest. Consistent with other studies, it lends empirical evidence to the notion that racial identity does not directly impact occupational interest. Witherspoon and Speight's study (2009) also appears to provide further evidence that men and women function differently with respect to occupational interests and self-efficacy. 
Quimby, Wolfson, and Selaya (2007) also attempted to assess the predictive value of social cognitive constructs on the career choices of African American students. Specifically, these authors measured the influence of cognitive, contextual, and outcome variables on African American adolescent interest in environmental science. Based on the tenants of SCCT, they hypothesized that investigative self-efficacy, outcome expectations, environmental attitudes, and perceived barriers would individually and collectively be predictive of student interest in environmental science as a career field.

For this study, 132 African American high school seniors (males $=57$; females $=75$ ) at a mid-Atlantic urban magnet polytechnic high school, who ranged in age from 16 to 18 years $(\mathrm{M}=$ $16.81, \mathrm{SD}=.45)$, were selected for participation. Of the 132 participants, $98.5 \%$ anticipated enrolling in a four-year college upon graduation, and nearly $87 \%$ indicated that they had already decided on a major. The 132 participants were selected from among 200 students enrolled in a mandatory math course.

In order to assess domain-specific constructs, the authors modified existing instruments to fit the needs of the study. Reliability and validity for the modified instruments were established with a sample of ethnic minority undergraduate science majors at a mid-Atlantic university. Measures included career interest in environmental science, investigative selfefficacy, outcome expectations, career barriers, perceived support, environmental concerns (which assessed participants' interest and agreement with environmental issues), and demographic data. A regression analysis was performed to determine the influence of these factors on interest in environmental science careers. The factors were found to collectively explain $24 \%$ of the variance in interest $(p<.001)$. The only significant individual predictor of interest, however, was investigative self-efficacy. 
In another study of specific career and academic interests among African American students, Lent et al. (2005) assessed social cognitive factors as predictors of interest and goals in engineering. Participants in this study were 487 students in introductory engineering classes at three eastern universities. Two of the three universities were historically Black colleges (HBCU). The 221 students from HBCUs included 150 males and 70 females (one student did not indicate gender), and they had a mean age of 19.13 years $(\mathrm{SD}=2.14)$. percent of the participants from the HBCUs, 87\% self-identified as Black or African American, 2\% as White or European, $2 \%$ as Native American, $1 \%$ as Hispanic, and 1\% as Asian or Asian American. Of the remaining 266 students coming from the predominantly White institution (males = 214; females $=52)$, the mean age was 18.52 years $(\mathrm{SD}=2.53) ; 9 \%$ of the students self-identified as Black or African American, 63\% as White or European, 3\% as Hispanic, 22\% as Asian or Asian American, and 3\% self-identified as other races.

Variables in this study included self-efficacy, technical interest, outcome expectations, major choice goals, and support and barriers related to pursuit of a major in engineering. Demographic data were also collected. The purpose of the study was to assess the degree of fit of SCCT models in predicting career choices across gender and university type. The rationale for the study was that environmental factors consistently show a degree of influence on choice among women and minorities. Persistence in the science, technology, engineering, and mathematics (STEM) fields among these populations, the authors posited, may be a function of environmental factors. Despite the fact that SCCT's tenets do not include a claim of a significant difference in the impact of environmental factors with respect to gender, the authors believed that assessing the differences among genders and across university type might bear fruitful findings (Lent et al., 2005). 
Results of a series of MANOVAs indicated that students at the two HBCUs had significantly higher $(p<.05)$ academic self-efficacy, outcome expectations, technical interests, social support, and goals than students at the predominantly White university (Lent et al., 2005). Site and gender interaction, however, were statistically non-significant. Students at all three universities did not differ significantly in experience of social barriers. Women did differ significantly from men on two variables, experiencing increased support and weaker social barriers. Overall analysis of variables revealed that self-efficacy and outcome expectations accounted for $37 \%$ of the variance in interest. Self-efficacy was the strongest predictor of goals. Neither support nor outcome expectations were individually predictive of goals. Support and barriers were interrelated and jointly predictive of self-efficacy $\left(r^{2}=.29\right)$. Tests of the goodness of fit for the hypothesized SCCT model in the prediction of academic interest indicated good fit, with no significant difference between males and females, indicating that the model fits both genders equally. The difference between the participants from the HBCUs and the predominantly White university was also tested and yielded results that suggested that the only significant difference in goodness of fit in the predictive models was the covariance between support and barriers. This suggests that the major difference in the path toward career interest of men and women at HBCUs and predominantly White universities is the experience of barriers and support at the two types of universities, such that students at HBCUs report experiencing greater support and students at predominantly White universities experience greater barriers to success. This finding lends credibility to the idea that support plays an important role in the formation of interest and may be impacted by the racial makeup of a student's environment (Lent et al., 2005). 
Byars-Winston, Estrada, Howard, Davis, and Zalapa (2010) set out to measure the influence of cognitive, cultural, and contextual factors on interest and career goals in STEM fields. However, the authors did not study a single minority group, but rather studied participants from a range of minority backgrounds. African American, Latino/a, Southern Asian, and Native American (ALANA) undergraduate students $(n=223)$ were included in this multiplegroup analysis. Students were either biological science (BIO) or engineering majors (ENG). To participate in the study, students were required to self-identify as African American $(n=55)$, Latino/a $(n=62)$, Southern Asian $(n=49)$, Native American $(n=8)$, or bicultural $(n=48)$. Students ranged in age from 18 to 39 years $(M=20)$, and gender was relatively evenly represented $($ males $=117 ;$ females $=104 ;$ unidentified $=2)$.

Students were given a survey packet that included demographic information; measures of science, math, and engineering-related constructs; and race and ethnicity measures. The academic measures were chosen based on their validity established in previous SCCT studies. Academic self-efficacy, outcome expectations, perception of campus climate, STEM degree goals, ethnic identity, and other group orientation were all measured. Several hypotheses were tested based on SCCT constructs and previous research. The major purpose of the study was to test a predictive model of the relationship of SCCT variables with interest in STEM fields.

Consistent with previous research, self-efficacy and outcome expectations had a positive relationship to STEM interest among all racial groups. Also consistent with previous research, the researchers found that ethnic identity was not significantly associated with perception of campus climate, self-efficacy, or outcome expectations (Byars-Winston et al., 2010). 


\section{SCCT and Gender}

Social Cognitive Career Theory and the broader self-efficacy theory from which it stems have not only been measured with respect to differences in race and ethnicity; an argument has been made within the literature for the differential treatment of SCCT factors on the basis of gender (Betz \& Hackett, 1981; Flores, O’Brien, 2002; Hackett \& Byars, 1996). In a study that predates SCCT, Betz and Hackett (1981) set out to determine the usefulness of self-efficacy theory in the understanding of female career development. Specifically, the researchers investigated the relationship of occupation-related self-efficacy to perceptions of occupational opportunities in men and women. They also investigated gender differences in self-efficacy with regard to educational requirements and job duties in traditionally male occupations.

To investigate these hypotheses, 20 common occupations were chosen to represent various interests. These interests varied according to Holland themes (Holland, 1973) and were chosen along a continuum of traditional and nontraditional female roles. Occupations were placed into categories of traditional or nontraditional based on the number of women reported to be in those occupations (U.S. Women's Bureau, 1975). Only occupations in which at least 70\% (traditional) or at most 30\% (nontraditional) of their workforce was female were used in the study. Two measures of self-efficacy were used. One related to self-efficacy with respect to educational requirements. The other related to job duty requirements of a given occupation. These measures were administered to 134 female and 101 male $(n=235)$ undergraduate psychology students.

Statistically significant differences in gender were found in the way men and women assessed their own ability to complete the educational and job-related tasks in 10 of the 20 jobs listed. Males reported significantly higher self-efficacy beliefs on five nontraditional 
occupations (accountant, drafter, engineer, highway patrol officer, and mathematician). Women reported higher self-efficacy beliefs on five traditional occupations (dental hygienist, elementary school teacher, home economist, physical therapist, and secretary). Still, some nontraditional occupations (like physician and lawyer) did not fit the pattern of lower self-efficacy beliefs among women. The authors pointed out that while these results indicate a strong and consistent difference in self-efficacy beliefs based on gender, this relationship does not appear to purely be a function of low expectations limiting career choices (Hackett \& Betz, 1981). Because women in the study displayed self-efficacy beliefs equal to men in some nontraditional occupations, the authors called for further investigation of this phenomenon. This study, however, was important in that it provided evidence for a fundamental difference in the self-efficacy beliefs of men and women.

In a later study (Betz \& Hackett, 1983), the same authors attempted to gain further knowledge on the differences in self-efficacy expectations between men and women. In this study, the authors investigated the relationship between mathematics self-efficacy and selection of science-based college majors. It was hypothesized that males would have stronger mathematics self-efficacy beliefs and that these beliefs would be directly related to choices in majors in both genders.

In gathering this information, 153 female and 109 male $(n=262)$ undergraduate students completed the Mathematics Self-Efficacy Scale, the Bem Sex Role Inventory (Bem, 1974), and a questionnaire about college major choices. Consistent with the hypothesis, males consistently showed stronger mathematics self-efficacy beliefs than females on individual items and across instruments. The subscales from the mathematics self-efficacy scale were also used as predictor variables in a multiple regression analysis predicting college major choices. The variables 
accounted for $36 \%$ of the variance, with a multiple regression coefficient of $R=.62$. These findings, once again, offer weight to the suggestion that, at least in certain fields, male and female self-efficacy beliefs are significantly different (Betz \& Hackett, 1983). More investigation may be needed to determine how broadly this finding can be viewed.

\section{Self-Efficacy and Achievement}

The cited research creates a strong case for a connection between self-efficacy and interest. Still, there may be a far more important relationship to be established within research on self-efficacy. A predictive relationship between self-efficacy and actual performance outcomes was indicated by early research on academic self-efficacy (Lent, Brown, \& Larkin, 1984; 1986; Multon, Brown, \& Lent, 1991). This information could prove valuable in the establishment of a need for initiatives to improve self-efficacy.

Lent, Brown, and Larkin (1981) set out to test Bandura's (1977) claim that self-efficacy has a significant impact on performance accomplishment and persistence. In order to do so, the researchers assessed the relationship between self-efficacy beliefs and academic success and persistence among students considering science and engineering careers. Student self-efficacy beliefs for completing educational requirements and job duties related to their chosen careers were assessed at the beginning, end, and two months after a 10 -week academic course. It was hypothesized that students with higher self-efficacy beliefs would be more likely to continue in and have greater success in subsequent courses than those with lower self-efficacy ratings. Relationships between self-efficacy and subjective measures of academic success, as well as differences among male and female participants, were also considered (Lent et al., 1984).

The study's participants were 28 male and 14 female undergraduate students enrolled in a career/educational-planning course for students considering careers in science and engineering. 
Students had a mean age of 20 years $(\mathrm{SD}=3.5)$ and were primarily freshmen and sophomores. Participants completed several measures of academic self-efficacy at pre-course, post-course, and follow-up points. Academic data were collected through university records, including Preliminary SAT (PSAT) scores, high school rank, college grades, and declared majors.

Using the self-efficacy ratings from the follow-up, participants were divided into high and low self-efficacy groups. When available, academic data, such as overall GPA, number of quarters completed, science or technology GPA, and completion of courses, were used to establish means and standard deviations among groups. Significant mean differences were found between students on level of self-efficacy for educational requirements (Hotelling's $T^{2}=11.93, p$ $<.05$ ) and strength of educational requirements (Hotelling's $T^{2}=18.48, p<.01$ ). Univariate $t$ tests also revealed significant differences between high and low self-efficacy groups in all but one variable. The only difference that was not statistically significant was technical GPA. All differences favored high self-efficacy beliefs. Students who reported higher self-efficacy beliefs generally performed better and persisted longer in their academic programs. Self-efficacy ratings were also related to objective measures of academic success, such as PSAT scores and high school rank. Differences based on gender did not reach significance, although the authors pointed out that these numbers should be interpreted with caution, given the small sample size $(n$ $=42$; Lent et al., 1984).

The same authors (Lent et al., 1986) later attempted to expand the growing body of knowledge about the predictive value of self-efficacy as it relates to academic performance and retention. The study was also designed to revisit the relationship between self-efficacy and perception of career choice among science and engineering students. Specifically, the study was designed to measure the utility of self-efficacy, ability, achievement, and interest as predictors of 
academic success, persistence, and range of perceived career options within the science and technology fields.

For this study, 105 students $($ male $=75$; female $=30$ ) were selected from one of two sections of an undergraduate career-planning course in science and engineering. Participants completed measures of self-efficacy, career indecision, self-esteem, expressed vocational interest, and range of perceived vocational options in science/technology. Academic information, such as high school rank, PSAT scores, college grades, and declared college majors, was obtained through university records.

The relationship between self-efficacy, vocational interests, and traditional predictors of academic success were calculated. High school rank and math PSAT scores were used as objective indices of aptitude and achievement. Correlations between measures of self-efficacy and the objective data were low or non-existent, indicating that the measures of self-efficacy reflected related, but slightly different, aspects of efficacy for academic performance (Lent et al., 1986). Although mean difference data comparing high self-efficacy groups to low self-efficacy groups yielded a significant correlation between self-efficacy and academic performance, a hierarchical regression analysis was needed in order to reveal the unique contribution of selfefficacy to academic performance above objective measures of academic ability and achievement.

When looking at technical GPA, high school rank and PSAT scores contributed greatly to the explained variance; however, self-efficacy also contributed additional significant variance. When assessing academic persistence, as measured by the number of academic quarters completed, high school rank and self-efficacy were the only significant predictors, with selfefficacy contributing significant variance beyond high school rank. A separate regression 
analysis was conducted to test the relationship of self-efficacy and other predictors to perceived range of technical career options. Results indicated that only interest and self-efficacy increased the multiple correlations of this equation and that self-efficacy added unique variance beyond interest. Both math PSAT scores and high school rank were found to have weak correlations with perceived career options ( $r=.14$ and .15 respectively), while interest $(r=.56, p<.001)$ was significantly correlated with perceived career choices. Academic milestone self-efficacy $(R=$ $.61, p<.01)$ and strength of self-efficacy $(R=.62, p<.001)$ were both significantly correlated with perception of career options. These results collectively provide strong evidence that selfefficacy is a unique predictor of academic performance and persistence along a chosen career path (Lent et al., 1986).

Multon, Brown, and Lent (1991), in an attempt to organize the growing body of research on the relationship between self-efficacy and academic outcomes, performed a meta-analysis of the existing research. The analysis was broken into two investigations. The researchers first investigated the relationship between self-efficacy and academic outcomes within the literature. Their second investigation focused on the relationship between self-efficacy and persistence. The effect size in both investigations was calculated using $r_{u}$, the unbiased correlation between the variables of interest.

In total, 38 studies of academic performance available at the time of the analysis yielded 38 samples suitable to be analyzed for effect size. The samples included 4,998 subjects across 38 studies $(M=131.5)$ with an average age of 16.6 years $(S D=12.6)$. Nineteen different academic performance measures were used in the studies. These measures fit into three major categories: (1) standardized achievement tests, (2) classroom-based measures, and (3) basic skills tasks. Experimental studies of self-efficacy interventions made up 19 of the 38 studies. These 
experimental studies, however, lacked the pretreatment data needed to calculate effect size; thus, post-treatment data were used in these 19 studies. The calculated unbiased effect size estimate in these studies was $.38(\mathrm{z}=28.22, p<.001)$. This result supported the hypothesized positive relationship between self-efficacy and academic performance despite significant heterogeneity among effect sizes (Multon et al., 1991).

There were 18 studies used in the investigation of relationships between self-efficacy and persistence, of which 15 were also used in the academic outcomes meta-analysis. These 18 studies yielded 18 different samples with a total of 1,194 participants $(M=66.1)$, ranging from 9.1 years to 20 years of age $(M=11.9)$. Within these studies, persistence was measured as either time on task, number of items or tasks attempted or completed, or number of academic terms completed. Fourteen of the studies were experimental in nature. As with the outcomes metaanalysis, posttest data were used to calculate effect size due to a lack of sufficient pretest data in experimental studies. Results indicated an overall effect size between self-efficacy and persistence of $.34(\mathrm{z}=11.75, p<.001)$. As with the academic outcomes analysis, the persistence investigation yielded great heterogeneity of effect sizes (Multon et al., 1991).

The results of these analyses provide strong support for the hypothesized influence of self-efficacy on academic performance and persistence. In addition, the heterogeneity of effect sizes indicates that the relationship between self-efficacy and academic outcomes and persistence may very across races, age groups, student types, and other characteristics. The authors indicated a need for investigation into methods of promoting self-efficacy within students and perhaps even in the workplace (Multon, et al., 1991).

Although no independent reviews of this meta-analysis were found, the authors did point out a number of limitations to their study. First, the authors pointed out that existing literature 
may not adequately test Bandura's (1986) theory with respect to the relationship of persistence and self-efficacy. According to Bandura, self-efficacy should be positively correlated with persistence in any given task. However, Multon and colleagues pointed out that the studies included in this meta-analysis generally failed to test persistence under maximally challenging conditions. Therefore, the authors suggested that future researchers attempt to utilize a design that allows for true testing of the persistence and self-efficacy relationship (Multon et al., 1991).

The authors also pointed out that the results of the study were somewhat compromised by less than optimal data reporting. Of the four moderators identified in the analysis, the authors noted that there are likely to be interactions that were unable to be tested due to insufficient data. Several studies needed to be removed from the analysis due to their lack of reporting sufficient data to accurately calculate effect sizes. Many of the studies used in the analysis did not report data that allowed for the calculation of pre-treatment and post-treatment effect sizes. The authors therefore recommended that future researchers ensure sufficient reporting of summary data in subsequent studies (Multon, et al., 1991).

A recent study also cited self-efficacy as an influencing factor in African American males' preparation for STEM majors in college (Strayhorn, 2015). The author used both qualitative and quantitative data to identify what factors influence African American male college students and enable their success in STEM fields. Results of the study indicated that self-efficacy was an important component in the success of African American males entering these fields of study.

In assessing the factors that influence college preparation for STEM fields, Strayhorn (2015) utilized a sequential mixed method design. The study surveyed 140 African American male undergraduate students in two phases. In the first phase, a web-based survey was used to 
measure aspects of students' college experience. This questionnaire collected data on four major areas: demographic information, student engagement, student transition, and non-cognitive traits. These data were compared to student ACT scores, GPA, educational aspirations, and various other information. In the second phase, in-depth one-on-one interviews were used to elicit stories about participants' college or STEM field experiences. Interviews were transcribed and analyzed in order to find categories or themes that had emerged among participants.

Results of this study yielded a number of interesting findings. Black male student perception of academic self-efficacy was positively correlated with ACT scores $(r=0.26 p<$ $0.01)$ and college GPA $(r=0.23, p<0.01)$. Academic self-efficacy was not correlated with high school GPA $(r=0.04, p>0.05)$, college academic major $(r=-0.04, p>0.05)$, or sense of belonging $(r=0.13, p>0.05)$. Interview participants stressed the role that academic selfefficacy plays in their success academically and in the STEM fields. Participants commonly used words like "confidence," "endurance," and "feel like I can do it" in describing the internal drive that motivates them to achieve academically, persist after setbacks, and follow through in the STEM major despite a lack of African Americans in these fields (Strayhorn, 2015).

These results offer further evidence that self-efficacy has a significant impact on the preparedness and performance of African American students. Through both qualitative and quantitative methods, the study illustrates the relationship between pre-college self-efficacy beliefs and college performance as well as attitudes and interests in college. Strayhorn's (2015) study also adds weight to the importance of self-efficacy improvement among African American students. With an abundance of evidence supporting the impact of self-efficacy on academic outcomes, research on self-efficacy improvement appears to be a natural next step. 


\section{Improving Self-Efficacy}

Although the cited literature establishes a firm link between self-efficacy and career interest, academic performance, and persistence, less attention has been directed at how to increase self-efficacy of minority students. Still, recent literature has emerged that attempts to understand self-efficacy improvement among students (Bullock-Yowell, Andrews, \& Buzzetta, 2011; Edman, 2009; Grier-Reed, \& Ganuza, 2011; Gushue \& Whitson, 2006; Shin, 2011). These studies have been designed to include a number of different variables that may help explain different levels of self-efficacy within student populations.

Gushue and Whitson (2006) began to address this question in their study of African American high school students. The purpose of their study was to investigate the impact of social support (i.e., parent/teacher support) and ethnic identity on career decision self-efficacy and outcome expectations. In order to study this relationship, 104 African American female ninth grade students ranging in age from 13 to 16 years $(\mathrm{M}=14.3, \mathrm{SD}=.56)$, from a northeastern U.S. public high school were given a battery of six instruments to complete.

The Multigroup Ethnic Identity Measure (MEIM; Phinney, 1992) was used to measure adolescent racial identity development. The MEIM consists of four subscales, only one of which was used in the reviewed study. The Ethnic Identity Subscale consists of 14 of the 20 items on the MEIM and was reported to have an alpha coefficient of .81 in a multiethnic sample of high school students (Gushue \& Whitson, 2006). The Parent Support Scale was used to measure students' feelings of support from parents. This 13-item measure consists of the Father Support Subscale and the Mother Support Subscale. A pilot study on the scale produced Cronbach's alpha coefficients of .72 for the Mother Support Subscale and .79 for the Father Support Subscale. The Teacher Support Scale was used to measure student perceptions of teacher 
support. This six-item scale yielded a Cronbach's alpha coefficient of .65 for the current study. Career self-efficacy factors were measured with the Career Decision Self-Efficacy Scale, which is a 25 -item short form of a 50 -item scale. The 25 items comprise five subscales. Internal consistency ratings have ranged from .92 to .97 in validation studies (Gushue \& Whitson, 2006). The level of positive expectations held by students with regard to career paths was assessed through the Outcome Expectations instrument. The six-item scale was designed to measure levels of positive expectation regarding the outcomes of career paths. With Gushue and Whitson's sample, the scale yielded a Cronbach's alpha coefficient of .68 (Gushue \& Whitson, 2006).

A multivariate multiple regression analysis was used to assess ethnic identity, parent support, and teacher support as predictor variables, with self-efficacy and outcome expectations as criterion variables. Parent support (Wilks's $\lambda=.93, F(2,99)=3.50, p<.05, \eta_{\mathrm{m}}=.07$ ) and teacher support (Wilks's $\lambda=.90, F(2,99)=5.77, p<.01, \eta_{\mathrm{m}}=.10$ ) were both found to be significant predictors. The relationship between ethnic identity and the criterion variables was not significant. Deeper analysis revealed that parent support had a significant positive relationship to career decision self-efficacy, $F(1,103)=6.72, p<.01, \eta=.06$, while teacher support had a significant positive relationship with both career decision self-efficacy, $F(1,103)=$ $10.68, p<.01, \eta=.10$, and outcome expectations, $F(1,103)=5.31, p<.05, \eta=.05$. These findings support SCCT and the idea that a supportive environment fosters increased self-efficacy and outcome expectations in African American students (Gushue \& Whitson, 2006). This study is also a helpful starting point in the understanding of the complex constellation of factors that create strong self-efficacy beliefs within a student. 
Although most studies of academic self-efficacy focus on adolescent or young adult populations, the author of a recent study took a rare look at possible predictors of academic selfefficacy among younger students (Shin, 2011). The study was designed to examine the impact that racial identity, Africentric values, and neighborhood satisfaction have on academic selfefficacy among elementary school students.

To test these relationships, 88 African American third graders $($ male $=35$; female $=53$ ) enrolled in a magnet elementary school in the northeastern United States, were recruited for the study as part of a larger community-university partnership aimed at revitalizing the targeted neighborhood. All of the students were residents of an under-resourced neighborhood (mean household income was $\$ 10,000$ ), and $80 \%$ of the participants qualified for free or reduced lunch. The mean age of participants was 8.24 years (range $=7$ to $10 ; \mathrm{SD}=.69$ ). The researcher collected basic demographic information and also administered four measures: Academic SelfEfficacy, Child Racial/Ethnic Identity, Africentric Values, and Neighborhood Satisfaction. Africentric values were defined as collective work and responsibility, cooperative economics, and self-determination (Belgrave et al., 1997).

A stepwise regression analysis was used to analyze the data. Academic self-efficacy was listed as the outcome variable, and racial/ethnic identity, Africentric values, and neighborhood satisfaction were the predictor variables. Consistent with previous studies cited herein, racial identity was removed from the final model as it did not account for a significant amount of variance. Africentric values, however, were significantly predictive of academic self-efficacy $\left(r^{2}\right.$ $=.26), F(3,84)=9.76, p<.01$. Neighborhood satisfaction was also included in the final model $\left(r^{2}=.33\right), F(4,83)=10.08, p<.01$. In total, the two variables accounted for $33 \%$ of the variance in explaining academic self-efficacy beliefs in the studied sample (Shin, 2011). Shin also 
pointed out that participants who reported a stronger awareness of and connection to family, community, and culture also reported increased confidence in their own abilities to succeed academically. This finding could be important in the establishment of intervention techniques for this population of students.

Other researchers have attempted to understand differences among gender and ethnic groups with respect to academic self-efficacy and other variables. Edman and Brazil (2009) hypothesized that ethnic minority students would report negative attitudes toward campus climate and lower levels of social support than Caucasian students. They also predicted that ethnic minority students would report lower levels of academic self-efficacy than their Caucasian counterparts. Finally, Edman and Brazil hypothesized that campus climate, student support, and academic self-efficacy would correlate with academic success as measured by college GPA.

The study included 475 volunteers from community college (50 African American, 146 Caucasian, 204 Asian, and 75 Latino/a). A survey to assess campus climate, social support, and self-perceptions was administered. The survey included the following instruments: Cultural Congruity Scale, College Environment Scale, Academic Self-Efficacy Scale, Mentoring Scale, and Social Support Scale. The authors reported alpha coefficients on these scales ranging from .78 to .89 for their sample (Edman \& Brazil, 2009).

Several analyses of variance were conducted in order to assess differences among ethnic groups and across gender (Edman \& Brazil, 2009). African American and Caucasian students reported significantly higher academic self-efficacy beliefs than other groups $(F(3,412)=9.39 ; p$ $<.001)$. African American and Caucasian students also scored higher on the Cultural Congruity Scale $(F(3,347)=9.75 ; p<.001)$. No ethnic differences were found for College Environment, Mentoring, or Social Support scales; moreover, no gender differences were found. 
Using data acquired by the institutional database, the researchers (Edman \& Brazil, 2009) calculated semester and cumulative GPAs and compared them among groups. Significant differences were found among the ethnic groups for both GPA categories. Caucasian students had a mean semester GPA of $2.53(\mathrm{SD}=1.07)$, while Asian students had a mean GPA of 2.26 $(\mathrm{SD}=1.10)$, followed by Latino/a students $(\mathrm{M}=1.98 ; \mathrm{SD}=1.14)$, and African American students $(\mathrm{M}=1.85 ; \mathrm{SD}=1.15)$. Cumulative GPA scores followed a similar pattern.

Pearson correlations were calculated in order to identify any relationships that may have emerged between GPA and other measured variables. Among Caucasian students, college environment was positively correlated with cumulative GPA $(r=.197, p<.01)$. Among Asian students, academic self-efficacy was significantly correlated with both semester GPA $(r=.244, p$ $<.01)$ and cumulative GPA $(r=.223, p<.01)$. Among Latino/a students, cultural congruity and college environment were both significantly correlated with semester GPA $(r=.352, p<.01 ; r=$ $.378, p<.01)$. Academic self-efficacy, cultural congruity, and college environment were also significantly correlated with cumulative GPA among Latino students $(r=.328, p<.01 ; r=.362$, $p<.01 ; r=.387, p<.01)$. However, no scales were found to be significantly correlated with either semester or cumulative GPA among African American students (Edman \& Brazil, 2009).

As the authors pointed out, it is important to note that the results of this study are to be read with caution due to a number of issues (Edman \& Brazil, 2009). First, the underrepresentation of African American students in the study may have led to the lack of significant findings with respect to predictor variables. Also, the number of Latino/a and Asian students who reported English as their second language (ESL) may have contributed significantly to their scores on certain scales. Particularly, scores of ESL students on the Cultural Congruity Scale were found to be significantly different than non-ESL students 
$(F(1,213)=11.61, p<.001)$. Still, results of the study can be viewed as lending some support to the notion that satisfaction with environment and academic self-efficacy are positively correlated with academic outcomes (Edman \& Brazil, 2009). One important finding of this study, however, may be that different ethnic groups seem to respond differently to these variables and may, therefore, need to be handled differently with respect to intervention approaches.

Bullock-Yowell, Andrews, and Buzzetta (2011), unlike previous researchers, attempted to connect self-efficacy beliefs to more individualized factors within African American students. In order to increase understanding of the effects personality and dysfunctional career thinking have on forming career decision-making self-efficacy, these authors set out to test the following hypotheses among a sample of African American college students: (1) personality factors and career thoughts will account for significant variance in career decision-making self-efficacy, and (2) after controlling for personality and career thoughts, cultural mistrust will account for a significant amount of variance in career decision-making self-efficacy.

A total of 322 undergraduate college students were recruited from a university in the southern United States. The participants were 77 men and 245 women, ages 18 to 51 years $(\mathrm{M}=$ 21.01, $\mathrm{SD}=4.75$ ). Of the 322 participants, 174 self-identified as African American, and 142 self-identified as Caucasian. The six remaining participants identified as Asian, Hispanic, or another ethnicity. One participant was a graduate student, 127 were freshmen, 81 were sophomores, 56 were juniors, 55 were seniors, and one student did not specify college year (Bullock-Yowell, Andrews, \& Buzzetta, 2011).

Participants were given a series of instruments that measured career decision-making self-efficacy, negative or dysfunctional career thoughts, Big Five personality factors (openness, conscientiousness, extraversion, agreeableness, emotional stability), and cultural mistrust. A 
multiple regression analysis was conducted to assess variance in career decision-making selfefficacy that could be accounted for by the predictor variables. Relationships between career decision-making self-efficacy and career thoughts and Big Five factors were explored in the full sample. Only African American students were used in the exploration of the amount of variance in career decision-making self-efficacy accounted for by cultural mistrust after controlling for career thoughts and Big Five factors. Career decision-making self-efficacy was found to be positively correlated with all Big Five personality factors and negatively correlated with negative career thoughts and cultural mistrust. Among the 174 African American participants, a hierarchical regression analysis was conducted in order to determine if any variance in career decision-making self-efficacy was accounted for by cultural mistrust. Although cultural mistrust accounted for a significant amount of variance (effect size .44), no unique variance was attributed to cultural mistrust after controlling for career thoughts and Big Five factors (BullockYowell et al., 2011).

Although the authors offered some information to the scarcely studied relationship between personality and self-efficacy, it is difficult to argue that this information could lead to viable solutions for intervention, as not enough is known about how to fundamentally change personalities in human beings. The finding that negative career thoughts are positively correlated with career decision-making self-efficacy is also a dubious finding in that it could be assumed that negative career thoughts are a function of career self-efficacy rather than a unique construct. The study does, however, add interesting knowledge to the link between racial identity issues and self-efficacy. The authors' rejection of their hypothesis that cultural mistrust would contribute uniquely to the prediction of self-efficacy beliefs among African American students may be seen as in line with previous findings that suggest racial identity is not 
significantly linked to self-efficacy among students (Byars-Winston et al., 2010; Lease, 2006; Witherspoon \& Speight, 2009). From this idea, found repeatedly within the literature, arises a perplexing question about the nature of self-efficacy beliefs in African American students: If self-efficacy within this population is not a function of membership in their racial group, how then do we explain differences that have been found between African Americans and other ethnic groups with respect to self-efficacy beliefs?

In order to understand this phenomenon, it may be useful to first explore the construct of racial identity. According to Sellers, Smith, Shelton, Rowley, and Chavous (1998, p. 19), racial identity in African Americans is "the significance of race in African Americans and the qualitative meanings they attribute to being members of that racial category." In other words, racial identity is the qualitative meaning, positive or negative, an individual places on his or her own membership in the race, as well as the degree of importance he or she places on that membership. Empirical evidence that this construct is not closely related to academic selfefficacy seems to indicate that, among African American students, membership in their racial group is not a factor in their personal success. Witherspoon and Speight (2009), in fact, found that students were not dissuaded from career aspirations by their perception that those career paths would lead to experiences of racism. This suggests that African American students' beliefs in their ability to accomplish academic tasks and follow career paths are not necessarily a part of what they use to define membership in their ethnic group. Therefore membership in the group, in and of itself, has no significant bearing on their self-efficacy beliefs.

Differences in self-efficacy beliefs among African American students, compared to their Caucasian counterparts, if not a function of racial identity, may be better explained through an understanding of Social Learning Theory. According to Bandura's (1986) original theory, self- 
efficacy beliefs and, more broadly, a person's choices, are a function of the triadic interaction between a person's cognitions, behaviors, and environment. If racial identity, which falls into the category of cognition, does not have the type of strong influence on self-efficacy that one might expect, researchers must then look to environmental factors to explain the phenomenon. In doing so, a number of facts emerge. As previously cited, African American students often receive differential feedback for their performances when compared to Caucasian students (Greene, 1990; Suarez-Balcazar, Orellana-Damacela, Portillo, Rowan, \& Andrews-Guillen, 2003). African American and other minority students are more likely than Caucasian students to be perceived as disruptive when interacting with non-minority teachers (Dee, 2005), which further contributes to the amount of negative feedback that minority students receive. Racial matching of teachers and students has been shown to improve reading and math scores for both minority and majority students (Dee, 2005), suggesting that minority students may be subject to decreased academic scores based on racial differences rather than performance differences. Considering the impact that environmentally sensitive factors like performance accomplishments, social persuasion, and vicarious learning have on self-efficacy, it may stand to reason that differences in African American student self-efficacy are less a function of membership in their race and more a function of how their race is treated in school.

The issue of racial identity and how it impacts self-efficacy having been addressed, the broader question about how we go about improving self-efficacy beliefs among African American students is left to be answered. A small number of researchers have attempted to do just that. Through interventions designed to increase or improve learning environments and experiences, researchers have explored what factors may have positive effects on self-efficacy in students. Liu, Hsieh, Cho, and Schallert (2006) investigated the use of a computer-enhanced 
problem-based learning (PBL) system with middle school students. They hypothesized that student experiences with PBL in science would impact their attitudes toward and self-efficacy for learning science. Broadly speaking, PBL is a process in which students are presented with problems and asked to apply reasoning, questioning, researching, and critical thinking in order to find solutions. It is designed to develop higher-order thinking skills. The focus of PBL tends not to be on the outcome but rather on the process through which students learn to become independent thinkers. The method was originally designed for medical education, but has begun to spark interest in other learning settings (Liu, Hsieh, Cho, \& Schallert, 2006).

Participants were 549 sixth graders from two middle schools in a southwestern U.S. city. Participants were 16\% Hispanic, 6\% African American, and 73\% Caucasian, with the remaining $5 \%$ coming from other ethnic backgrounds. Of the 549 students, 271 were female. The study took place over a three-week period in the $2^{\text {nd }}$ semester of the sixth-grade year. Students completed a CD-based hypermedia PBL program called Alien Rescue. The program was designed to immerse students in a complex task that required problem-solving skills and acquisition of knowledge about the solar system and scientific methods (Liu, Williams, \& Pedersen, 2002).

Analysis of variance (ANOVA) results with repeated measures indicated that science achievement $(F(1,463)=1214.96, p<.001)$ and science self-efficacy scores $(F(1,463)=12.61, p$ $<.001$ ) both increased from pretest to posttest. Attitudes toward science, however, did not change significantly. Consistent with cited literature, self-efficacy was also found to be predictive of science achievement $(\beta=.33, t(489)=6.02, p<.001)$. These findings suggest that the PBL system increased both achievement and self-efficacy in the group of sixth graders. It is difficult to determine what increases could purely be attributed to the intervention, however, due 
to the lack of a control group for comparison. It may be beneficial to replicate this study with a true experimental design in order to determine how much of the increase in self-efficacy can be attributed to the PBL system and how much is simply a function of learning (Liu et al., 2006).

Usher and Pajares (2006) also measured the degree to which methodological factors within a school setting could impact self-efficacy beliefs among young students. In this study, the researchers measured invitation and the possible predictive relationship it has with selfefficacy beliefs. The invitation theory of education suggests that people are able to send empowering messages to themselves and others and that these messages have an impact on achievement. Invitational education is defined as the process of summoning people to realize their own potential (Purkey \& Novak, 1996).

The participants were 468 sixth-grade students $($ male $=230$; female $=238$, ) attending two southeastern U.S. public schools. Of the 468 students, 263 were Caucasian, 165 were African American, 21 were Hispanic; 9 were Asian, and 10 were of other ethnicities. The instruments were group-administered to students during reading classes, and included measures of sources of self-efficacy, academic self-efficacy, invitation, and academic achievement. The authors intended to test the predictive properties of self-efficacy sources, as well as test invitation as a possible added source of self-efficacy beliefs (Usher \& Pajares, 2006).

A hierarchical regression analysis was performed to determine the contributions of the hypothesized factors. Because the sample of students came from two separate schools, the schools were entered as predictors in the first step of analysis in order to control for school effect. Bandura's (1997) four sources of self-efficacy were entered in the second step. The invitations were added in a third step. The interactions of school were found to be nonsignificant and were therefore taken out of the final model. 
Consistent with self-efficacy literature, all four sources of self-efficacy were significantly correlated with academic self-efficacy beliefs. Invitation of self $(r=.49, p<.001)$ and invitation of others $(r=.46, p<.001)$ were also both significantly positively correlated with academic selfefficacy. This finding is consistent with previous studies that have linked invitation to selfefficacy constructs (Valiente \& Pajares, 1999). Analysis of the results also offered interesting insights when comparing gender and ethnic groups. The four main sources of self-efficacy operated differently when comparing the genders. Social persuasion appeared to be more important to girls than to boys in forming academic self-efficacy. Usher and Pajares (2006) pointed out that this finding is consistent with a previous study that suggested women rely more heavily on the judgment of others in making career decisions (Zeldin \& Pajares, 2000). African American students also appeared to respond more to invitation when compared to Caucasians (Usher \& Pajares, 2006). Invitation accounted for $9 \%$ of the unique variance in African American students' self-efficacy beliefs. The fact that social persuasion continued to be predictive of academic self-efficacy among African American students, even when invitation was in the model, indicates an increased sensitivity to social relationships within this population. The authors suggested that this points to a need for a more "culturally sensitive pedagogy," in which institutions and teachers are more responsive to the needs, learning preferences, and abilities of the students they teach.

In another effort to implement a culturally sensitive approach to learning, Grier-Reed and Ganuza (2011) measured the impact of a constructivist career course on the career self-efficacy beliefs of 81 Asian American and African American college students. The constructivist approach requires that educators recognize that there is more than one worldview and focuses on helping people make meaning of their life experiences. The career course in the study 
incorporated narratives, action, construction, and interpretation. Activities included Early Career Fantasy, Identity Experiential Exercises, Career Genograms, Who Am I Experiential Exercises, and Reflective Writing. These activities allowed participants to explore their conceptions about career, self, and influential relationships they had experienced. The course met once a week for two hours over the course of a 15-week semester. Data were collected on all students who participated in the course over a three-year span.

The study took place at a large urban research university in the midwestern United States. Participants were 81 students enrolled in the course through the university's College of Education and Human Development. Of the 81 students, 36 were African American and 45 were Asian American. The participants' ages ranged from 18 to 28 years ( $M=19.65$, SD 1.59), and 51 participants were female and 30 were male. Students completed a measure of career decision self-efficacy at the beginning and end of the course. The Career Decision Self-Efficacy ScaleShort Form is a 25 -item Likert-type scale and consists of self-appraisal, occupational information, goal selection, planning, and problem solving subscales (Grier-Reed \& Ganuza, 2011). Psychometric properties for the scale were not included in the study.

A MANOVA was used to analyze differences in self-efficacy scores from pretest to posttest, and a significant difference was obtained $(F(5,76)=10.63, p<.001)$. Follow-up MANOVAs revealed significant pretest and posttest differences on all five subscales. Follow-up analysis also revealed that goal selection and planning accounted for the largest proportion of variance, while problem solving accounted for the smallest proportion of variance from pretest to posttest. No differences with respect to gender or ethnic groups were reported (Grier-Reed \& Ganuza, 2011). 
Results of this study offer hopeful empirical evidence for self-efficacy improvement through modified teaching environments. However, some design flaws in the study limit the amount of knowledge that can be taken from it. The lack of a control group for comparison of scores makes it difficult to suggest with certainty that the changes in self-efficacy beliefs experienced by students were a product of the teaching method as opposed to the course content itself, the student relationships with instructors, or other factors related to completing a college semester. Also, the small sample size limits the degree to which we can interpret effect size. Still, the study's results offer hope for any course of intervention aimed at empowering students and improving self-efficacy (Grier-Reed \& Ganuza, 2011).

Denson (2010) attempted to assess the impact of a mentoring program on African American male high school students' perception of engineering as a potential career. Citing Kram's (1983) mentoring theory in which Kram posited that mentoring is a relationship in which an experienced member of an organization acts as a role-model for and provides support to a protégé, Denson (2010) posited that mentoring would have a significant impact on students' perception of engineering as a career option, as well as their self-efficacy with respect to pursuing the career path. Unlike many other studies of this kind, however, Denson was able to employ an experimental design in order to isolate the effect of the intervention.

African American male students from an alternative high school in North Carolina were randomly selected and randomly assigned to treatment and control groups. Although 20 students were assigned to each of the two groups, only 15 members of the treatment group were able to provide parental consent for participation in the study. Thus, the control group was reduced to 15 members in order to match the number of participants in the treatment group. The researcher recruited active members of the National Society of Black Engineers to serve as mentors for the 
treatment group. Mentors met with participants for two one-hour mentoring sessions per month for four months. These mentoring sessions were focused on addressing three major concerns: (1) a lack of exposure among young African American students to the STEM fields; (2) absence of role-models; and (3) differences in learning styles (Denson, 2010).

This study used a posttest-only design due to concerns that the pretest would affect participant scores on the posttest. The instrument, which was designed specifically for the study, measured student perceptions and self-efficacy related to engineering, confidence and selfbeliefs about math in engineering problems, and confidence and self-beliefs about science in engineering problems, as well as collecting background data and feedback about mentors. Due to attrition, only 24 students completed the study, and only 20 completed usable surveys. The treatment and control groups both consisted of 10 self-identified Black/African American male students.

Independent samples $t$ tests were performed to determine differences between the treatment and control groups at posttest. The research tested three major questions. First, student perceptions of engineering were compared. Although the treatment group did show a higher mean score, it did not reach statistical significance, $(t[18, .05]=.399)$. Second, students' math self-efficacy related to engineering was compared. Again, despite elevated scores in the treatment group, this difference did not reach statistical significance at the alpha level of .05 $(t[18, .05]=.676)$. Lastly, a comparison of student science-related self-efficacy among mentored and non-mentored students also revealed no significant difference $(t[18, .05]=.220$; Denson, 2010).

Results of this study, despite the lack of significant findings about the effect of the mentoring program, may be helpful to future researchers. Exit interviews of participants in the 
study indicated that more time was needed in order to maximize impact of the mentoring relationships. The relatively limited time frame of the intervention may have greatly impacted the effect it had on participants' beliefs related to engineering. Also, the small sample size of the study made it very difficult to detect differences between the mentored and non-mentored groups. Future research, taking these factors into consideration, may prove fruitful (Denson, 2010).

When looking at the cited literature, certain concepts become clear. The field of psychology appears to substantiate the idea that self-efficacy is a strong predictor of academic choices, performance, and persistence. The empirical evidence of the importance of self-efficacy beliefs among minority students has been clear and consistent for some time. What is not yet evident is what complex constellation of factors creates or improves self-efficacy beliefs within this population. More specifically, a strong and reliable intervention for the improvement of career and academic self-efficacy beliefs has yet to be identified.

Several factors have been posited as viable sources of increased self-efficacy beliefs. Cultivation of Africentric values, supportive parents and teachers, supportive environments, and neighborhood satisfaction have all been offered as factors that may contribute to improved selfefficacy beliefs among African American students (Gushue \& Whitson, 2006; Shin, 2011). Researchers have suggested that an environment that offers culturally sensitive and uplifting messages to students would positively impact the way those students see their own abilities and choices for the future (Grier-Reed \& Ganuza, 2011; Shin, 2011; Usher \& Pajares, 2006). The question that remains is, what factors are necessary to create such an environment?

Role-Modeling. Despite a clear connection between self-efficacy theory and modeling (Bandura, 1986), there is very little data on the impact modeling actually has on self-efficacy 
beliefs among students. The limited amount of research on the relationship between rolemodeling and self-efficacy beliefs among students may be helpful to this discussion. Kafele (2012) indicated that U.S. schools are experiencing a "Role-model Crisis" with respect to African American male students. Using primarily experiential and anecdotal evidence, Kafele argued that this population, in particular, is lacking sufficient role-models to help improve their success. He also pointed to U.S. Census data (2012) that indicates 50\% of African American children live in homes without a father present.

Based on this trend, and the perceived need to increase African American male student exposure to same-race and same-gender role-models, Kafele, who was a principal at a Newark, New Jersey, school, created the Young Men's Empowerment Program (Kafele, 2012). The purpose of the program was to teach the principles of manhood to male students of all races. One of the initiatives of the program, Power Monday, had students dress in business attire every Monday, and male students in all grades participated in discussions and lectures presented by male staff members and community leaders. Although the author purported that the program was equally effective in diverse and racially homogenous schools, no empirical evidence of the impact of this program was offered in the article (Kafele, 2012).

Not everyone agrees that racial similarity among role-models is important. In a recent study of academic performance, Ainsworth (2010) presented data that may actually refute the importance of racial similarity in role-modeling. In order to test the theorized impact that samerace role-models might have (Bandura, 1986, p. 302), Ainsworth used National Educational Longitudinal Study (NELS) data to understand the impact that neighborhood context has on student performance in standardized testing. 
Three variables were used to define neighborhood context: high-status residents, residential stability, and economic disadvantage. The author used data from a longitudinal study of middle school students that tracked them to high school. By matching this data to U.S. Census data for the corresponding time periods, Ainsworth (2010) was able to test a series of regression models that were created to predict the impact that neighborhood context would have on academic performance.

Data from the 1988 NELS were used in conjunction with the 1990 U.S. Census. Statistics on 25 eighth graders from each of the roughly 1,000 randomly selected middle schools used in the study. Five separate regression models were conducted to test four research questions. First, do neighborhood characteristics influence educational achievement, and, if so, which characteristics are most important? Second, are Black and White students affected differently by these influences? Third, does the racial composition of positive and negative rolemodels in a neighborhood shape student performance differently? Finally, do Black and White students receive differential benefits from the presence of same-race role-models (Ainsworth, 2010)? Family background characteristics, such as family socioeconomic status, family structure, and number of siblings, were all used as control variables.

As the author had predicted, the number of neighborhood high-status residents, which were defined as college graduates over the age of 24 , was a significant predictor of student achievement $(p<.001)$. Neither residential stability nor neighborhood economic disadvantage were significant predictors of student achievement. When the interactions between (a) race and high-status residents and (b) race and economic disadvantage were tested, neither of these interactions was significant. This finding suggests that the neighborhood context did not impacted Black and White students differently (Ainsworth, 2010). 
When the model was adjusted to add racial interactions with same-race measures of highstatus residents and socioeconomic disadvantage, neither of these interactions was significant. These results seem to provide evidence for an argument against the need for racial similarity between role-models and students. Replication of this study with data collected directly from the students may help to ascertain the impact of racial similarity of role-models on students. This study addressed the impact of the racial composition of a neighborhood on student performance; it did not, however, control for the impact that same-race role-models within the home or school may have had on the students. Collecting data from students, rather than relying on previously existing data, may allow for a deeper understanding of the same-race role-modeling issue.

In light of the lack of empirical support for the relationship between role-modeling and academic outcomes or self-efficacy, researchers must speculate as to the cause of this gap in the literature. One explanation may be found in the trend that emerges within the existing literature surrounding SCCT. Similar to many issues relating to minority populations in education and psychology, there tends to be a lack of research interest and understanding of the salient issues. Much of the existing literature addresses issues in African American and Hispanic populations, as African American and Hispanic students tend to under-perform when compared to Caucasian and Asian students.

Researchers interested in further exploring the true relationship of role-modeling to selfefficacy, especially those with a goal of testing the merit of Bandura's original notion of similarity in role-models (Bandura, 1986) are forced to make loose connections between old research on self-efficacy and SCCT and that of role-modeling and student mentoring. As researchers appear to have been content to understand the impact that self-efficacy has on student performance and persistence or the impact that role-modeling programs have on academic 
outcomes, certain leaps must be made in understanding the connection between role-modeling and self-efficacy among students. These connections are explored below.

\section{Role-Models and Self-Efficacy}

Social Learning Theory suggests that modeling plays an important role in shaping a person's behavior, performance, learning, and attitude development (Bandura, 1986). Perhaps for this reason, role-modeling is indicated as an important component in much of the literature on self-efficacy and SCCT. Much of the literature that looks at career counseling and academic achievement for minority students points to role-modeling as a viable intervention (Credle \& Dean, 1991; Henry, Bardo, \& Henry, 1992). Bandura (1986) suggested a direct influence that modeling can have on self-efficacy when the modeled behaviors are relevant to the observer.

Role-modeling for African American adolescents has the potential to have a positive effect on all four of the information sources that create self-efficacy. Most obviously, rolemodeling directly impacts vicarious learning. By exposing adolescents to African American professionals, the adolescents are given an increased number of examples of academic and professional achievement by minority individuals. This phenomenon, which is noticeably lacking for minorities in U.S. schools and communities (Fries-Britt, Rowan-Kenyon, Perna, Milem, \& Howard, 2011; Madkins, 2011) would combat the faulty belief that African American students should limit their academic and career aspirations. According to a recent National Center for Education Information report (Feistritzer, 2011), African Americans made up only 7\% of all elementary and secondary school teachers in 2011. During roughly the same time period, African Americans made up 15\% of all elementary and secondary school students in the United States (National Center for Education Statistics, 2012). The National Center for Education Statistics (Hussar, 2013) projects that the number of Caucasian elementary and secondary 
students in the U.S. will decrease by $2 \%$ from 2010 to 2021 . During that same time period, they project that the number of African American students will increase by 5\%. Students of more than one race are projected to increase by 34\% (Hussar, 2013). These statistics are indicative of a growing need for minority teachers.

In order to fully understand the impact that same-race models might have on African American students, some attention must be paid to the idea of racial identity. African American racial identity, an idea pioneered by William Cross (1971) and later expanded by several African American psychologists (Helms, 1990; Cross, 1991; Helms \& Carter, 1991; Sellers, Smith, Shelton, Rowley, \& Chavous, 1998, p. 23), provides a framework for the meaning that a person places on membership in a particular group. Sellers and his colleagues defined African American racial identity as "the significance and qualitative meaning that individuals attribute to their membership within the Black racial group within their self-concept." In other words, this construct is a consideration of both how important it is to an individual that they are a member of the race and what exactly that membership means to them.

When considering the importance of race in modeling relationships, it would stand to reason that racial identity development serve as a moderator variable, such that racial identity would help determine the strength or importance of the model's race to the observer. Yet, consistent with the literature, racial identity and related constructs have proven to be non-factors in studies related to African American students and their career or academic choices (Lease, 2006; Shin, 2011; Witherspoon \& Speight, 2009). Although this research appears to indicate no impact of racial identity on the career or academic choices of African American students, the impact of race on role-modeling relationships remains unclear. With existing literature pointing 
to a void in African American models of professional success, the impact of increased exposure to such role-models is an idea worth exploring.

With African American role-models present, social persuasion would be similarly affected for the African American youth. Professionals who share a common culture and heritage with African American young people may be less likely to discourage them from career and academic goals. These role-models would likely become a source of encouragement as African American adolescents explore newfound career interests. These role-models could also have a positive effect on African American young peoples' physiological states. As the environment around them becomes more and more encouraging, African American youth, especially those accustomed to being in schools and other environments with few or no African American professionals, may feel increased comfort from being surrounded by same-race rolemodels. With an influx of African American role-models, personal performance accomplishments could also increase. These young people are likely to experience increased exposure to opportunities with a more culturally diverse group of role-models in their lives. With increased opportunity and exposure to experiences, African American adolescents would naturally accomplish more.

The idea of mentoring minority adolescents is not a new one. The power of modeling is well established with Bandura's (1986) theory. Perhaps based on that knowledge, formal programs like Big Brothers and Big Sisters of America (BBBSA) have been working to enrich the lives of at-risk and minority youth. Although these programs are generally based outside of the school systems, research has shown them to have a positive influence on school and career performance (Dubois, Holloway, Valentine, \& Cooper, 2002; Grossman, Roffman, \& Rhodes, 2002; Karcher, Kuperminc, Portwood, Sipe, \& Taylor, 2006). 


\section{Natural Role-Models}

A search of the recent literature reveals that researchers have begun to study the impact of informal, or "natural," mentoring. In these informal mentoring situations, adolescents choose mentors from the adults that are already in their lives (Gastic \& Johnson, 2009). Within the homes and communities of students, natural mentors are the family members that they see throughout their formative years. Parents, aunts, uncles, and cousins play an important role in exposing students to evidence of their own capabilities through vicarious learning and social persuasion. This is a central tenet of Bandura's (1986) theory of learning and self-efficacy. The presence of informal mentors who have achieved academic and career success will undoubtedly impact the way students perceive their own abilities, as well as shape their academic and career choices.

In the academic setting, natural mentors are the teachers, administrators, and staff that interact with the students on a regular basis. As with the home and community mentors, the presence of professionals whom African American students identify as mentors increases the likelihood that those students are positively impacted by the mentoring relationship. In any modeling situation, the observer is more likely to attempt to follow or model a figure with similar characteristics such as race, gender, or age (Bandura, 1986). It stands to reason, then, that in order to maximize the learning environment for an African American student, that environment must have a reasonable number of African American professionals to serve as models.

Credle and Dean (1991), through a review of existing literature, concluded that increasing the presence of minority faculty and administrators may increase the enrollment and retention of African American college students. They listed lack of awareness of the needs of African 
American students; inability to help African American students survive in the complex systems of the institution; and reactive, as opposed to proactive, responses to student needs among the many issues plaguing the United States' predominantly Caucasian colleges and universities. Some of the recommendations made to these institutions by Credle and Dean included developing mentoring programs, encouraging contact between African American professionals and students, and helping students adjust to and work within the systems that exist in the institution. In order to show strong commitment to the retention and success of African American students, the authors noted, institutions must show a commitment to the recruitment and retention of African American faculty, administrators, and staff (Credle \& Dean, 1991).

A study of minority pre-med students found that participation in a career development seminar facilitated by minority faculty increased feelings of school preparedness in the students (Henry, Bardo, \& Henry, 1992). The program placed $61($ male $=27$; female $=34)$ African American pre-med students in a three-part seminar designed to increase qualified medical school applicants among underrepresented groups. The seminar exposed students to an orientation course designed to help identify personal strengths and weaknesses, a medical portion that increased student knowledge of various medical school policies, and clinical experience that helped to expose students to the medical environment. Researchers administered the Medical Career Development Inventory (MCDI) as a pretest and a posttest. The inventory measures degree of vocational development and readiness to cope with developmental tasks associated with a medical doctor's career. The authors reported that reliability of the instrument was established using 160 student-physicians and that alpha coefficients ranged from .73 to .91 for the various subscales of the inventory (Henry et al., 1992). 
Results of the $t$ test for comparison of pretest and posttest scores suggested that the mean scores on all subtests on the scale were significantly higher at posttest than at pretest $(p<.01)$. Pretest mean scores were $116.04(\mathrm{SD}=16.74)$, while posttest mean scores were 133.80 $(\mathrm{SD}=17.85)$, suggesting that the group's absolute vocational development had increased. Although the design of the study lacks a control group, thus making it difficult to determine if the improvements in student development were caused by the mentoring program, the mentoring relationships, or other factors, the results point to a need for further investigation of these types of programs and the reasons for their success (Henry et al., 1992).

California State University, Dominguez Hills (CSUDH), through the Faculty Mentoring Program (FMP), paired minority college students with faculty mentors in an effort to improve achievement, retention, and graduation in at-risk students. Santos and Reigadas (2000) conducted a study of the program in order to understand the mentoring relationship and how it may impact academic adjustment. Surveys were mailed to 200 present and former mentees of the CSUDH FMP. A total of 65 students responded to the mailing. Only results from the Latino $(n=32)$ students were used in the study. Approximately half of the Latino students $(43.8 \%)$ were matched with a Latino mentor in the program. The remaining students were assigned to a mentor of a different ethnicity (e.g., African American or Caucasian).

The survey was a two-part instrument designed to measure college adjustment, as well as perceptions of the mentoring program. The $t$-test analysis of pretest and posttest scores suggested that Latino students with faculty mentors had increased academic self-efficacy and had better defined academic goals than they did before participating in the program. No mean changes in college anxiety were noted (Santos \& Reigadas, 2000). It is important to point out that the authors did not administer these measures at the start of the mentoring program, but 
rather researchers asked students to complete the surveys retroactively upon completion of the program; therefore, suggestions about changes in their self-efficacy beliefs should be read with caution. The results also suggested that ethnically matched mentoring pairs provided more increases in self-efficacy and more student satisfaction with the mentoring relationship than did non-ethnically matched pairs. While the reliability of the retrospective data calls into question the validity of any findings about changes in self-efficacy beliefs among the sample, the reported higher levels of satisfaction among ethnically matched pairs may be worth investigating (Santos \& Reigadas, 2000).

Still, the literature on teachers as role-models is not all positive. One study found that matching students with ethnically similar teachers may actually have a negative effect (Maylor, 2009). According to the study, the presumption that African American teachers are naturally equipped to be role-models for African American students could not only become an undue burden on African American teachers, but it could alienate students in situations where they are matched with teachers that they do not identify with as desirable role-models. Even researchers who have found role-modeling programs to have a positive impact have found it difficult to show true causation in their research (Linnehan, 2001). Others have had mixed results when exploring whether role-modeling programs have a significant impact on actual school performance (Holt et. al, 2008; Santos \& Reigadas, 2000). These findings have led some to suggest that the nature of the impact of mentoring is far more complex than can be measured by increases in school performance (Santos \& Reigadas, 2000). Some argue that the quality of the teachers, rather than their ethnicity, is far more important to the development of strong African American students (Maylor, 2009). 
The idea of increased mentoring for African American youth through an increase in African American teachers has been debated since the desegregation of U.S. schools. Scholars have suggested that one of the trade-offs of desegregation was the loss of the many African American teachers and administrators that were displaced in the process (Lyons \& Chesley, 2004). With the closing of many African American schools, African American students lost a valuable resource in the thousands of African American teachers who had been serving as natural role-models before desegregation. Since then, things have only gotten worse. A current look at U.S. schools points to two overwhelming facts. The first is that there are a rapidly increasing number of minority students in U.S. schools. The second, and perhaps more disturbing, fact is that the teaching force in the United States is not keeping pace with the changing student demographics. A recent report indicated that $85 \%$ of people enrolled in teacher preparation programs are Caucasian, while only 7\% are African American (McNulty \& Brown, 2009). This leaves African American and other minority students with disproportionate numbers of samerace role-models within the schools. This also means that any positive self-efficacy beliefs with respect to career and academic goals would be formed despite the lack of ethnically similar rolemodels encountered in this environment. Trends in graduation, standardized testing, college enrollment, and high school dropouts indicate that academic achievement among African Americans leaves much room for improvement, and statistics from the U.S. Department of Education suggest that intervention is needed. In 2010, African American students dropped out of high school at a rate of $8 \%$, compared to $5.1 \%$ among Caucasians and $4.2 \%$ among Asian Americans. However, African Americans accounted for the lowest number of Advanced Placement exam takers of any race in the U.S. from 1999 to 2008 (2010; 2012). I contend that 
self-efficacy improvement through teacher role-modeling could play a vital part in solving this problem.

Efforts have been made to address this issue. Programs designed to recruit African American teachers are ongoing. A mentoring program in South Carolina, entitled Call Me Mister, is aimed at recruiting and retaining African American teachers (Holensdolph, 2007). The program, primarily state funded, helps supply African American male teachers with tuition assistance. This program and others like it are administered privately and operate under the hope that they will create a larger pool of teachers for the schools they target. Still, the trends have not changed - there continues to be a trend toward a lack of minority teachers.

It is unclear whether or not existing role-modeling or mentoring programs are even having the desired long-term effects. Many of these programs are small and have not been attempted on a large scale. When implemented, it is difficult to speculate if the impact they have on student performance is a product of the intervention used or the mentoring relationships created. It would be important to establish the impact that natural mentors have on the lives of these students before arguing that external interventions of this type are needed. Whether or not having teacher role-models has a direct effect on academic self-efficacy is a question that has scarcely been asked, let alone answered, within the literature. Even with these questions answered, it is difficult to speculate how feasible a large-scale intervention designed to infuse role-models into the U.S. school systems would be. Affirmative action initiatives in the United States aimed at creating equity and proportionate representation of minorities in the workplace have been met with great political resistance over the years (Sánchez, 2015). Any effort sanctioned by schools or the state and federal government and charged with increasing African American teachers in schools could be viewed as yet another affirmative action program. 
Without government support, however, many schools lack the resources to effectively recruit and retain African American teachers. Given the burdens on schools to meet state and national academic standards, their focus is, perhaps understandably, elsewhere. Still, there appears to be a need for further investigation into this issue. With self-efficacy literature pointing to the need for positive role-models and the overwhelming lack of role-models for African American students, I believe that there is a gap to be filled.

The literature on African American students suggests that they may benefit from an infusion of same-race teachers and other role-models. The literature, however, does not provide a clear understanding of the precise nature of the impact modeling would have on the students and in what way this increase in models should occur. While literature on the impact of samerace teachers provides some support for the need for an increased number of African American teachers, no clear evidence has yet been offered to quantify the impact this increase would have. Based on the theoretical support Social Learning Theory provides for the impact of role-models on self-efficacy, the purpose of the current study is to provide greater understanding of the relationship of African American students to same-race role-models. Specifically, this study examined the impact same-race role-models have on career and academic self-efficacy among African American college students. It was hypothesized that career and academic self-efficacy would increase as the number of same-race models increased. 


\section{Chapter 2: Methods}

\section{Research Question}

Within the framework of Social Cognitive Career Theory (SCCT; Lent \& Brown, 1996) and its deeper foundation in the construct of self-efficacy, is the understanding that self-efficacy is built within the context of the social interaction between the person and the environment (i.e., learning experiences). This has particular significance for African American students. With this in mind, the proposed research attempted to answer the question: Does the number of same-race role-models an African American student encounters in daily life impact the student's career and academic self-efficacy? The following research questions were explored:

- Does the total number of same-race role-models experienced in childhood have a significant positive correlation with the career and academic self-efficacy beliefs of African American college students?

- Does the number of African American teachers in a student's life account for a significant proportion of variance in career and academic self-efficacy beliefs when controlling for family role-models?

\section{Design}

This study used a correlational design. All participants were given the same materials in order to complete the study. No comparison groups were created. At the core of the research question is the relationships among career and academic self-efficacy and same-race rolemodels. Two hypotheses were tested in this study:

$\mathrm{H}_{1}$ : Total number of same-race role-models will significantly predict career and academic self-efficacy scores. 
$\mathrm{H}_{2:}$ Number of African American teachers will provide unique variance in career and academic self-efficacy scores when controlling for family role-models.

This study used a predictive model in order to test the strength of the linear relationship between the variables of interest. Family role-models and teacher role-models were used as predictor variables, while career and academic self-efficacy was used as the outcome variable. Tests were administered to measure participant self-efficacy scores and to measure the number of same-race role-models in the participants' family. These scores were then used in the analyses of the stated hypotheses.

\section{Participants}

The participants of this study were African American students, at least 18 years of age, enrolled in universities in the Pittsburgh, Pennsylvania, metropolitan area. Data for this study were taken from the pilot study conducted in order to validate the Career and Academic SelfEfficacy Scale. A total of 310 participants took part in the validation study. Of the 310 participants, 87 identified as African American or of mixed races that included African American. According to Field (2009), a regression analysis with two predictor variables requires a minimum of 70 participants in order to detect a medium effect size. Therefore, the current study was deemed to have reached a sufficient number of participants to conduct the analyses.

All participants self-identified as either "Black/African American" or more than one race, including "Black/African American.” Of the 87 participants, 79 listed their ages, which ranged from 18 to 59 years $(M=23.24$, SD 7.76). Thirty-five participants, or $40.2 \%$, indicated that they were male, while 51 participants $(58.6 \%)$ indicated that they were female. One participant did not indicate gender. 


\section{Variables and Measures}

Career and academic self-efficacy. Because SCCT focuses on very dynamic and situation-specific concepts, the use of more universal, trait-oriented measures is often not practical (Lent \& Brown, 2006). SCCT researchers are often forced to create measures that attempt to address the specific aspects of self-efficacy in question. The current study is no exception. Much of the literature on self-efficacy focuses on academic goals or career goals, separately. However, the current study aims to address a student's fundamental belief in his or her ability to complete all tasks associated with following a career path from student to career professional, such as completing the degree, finding a job, and maintaining work within the chosen field. While previous research has tended to separate career goals from academic goals, it is my belief that in order to understand the impact of academic goals and decisions among college students, they must be looked at within the context of the greater career lens through which students actually make those goals and decisions. The choices that students make in college, with respect to majors, classes, and other academic tasks, have a direct impact on their career trajectory. Looking at career and academic self-efficacy together allows us to fully understand the impact a student's beliefs in their academic abilities might have on career decisions.

In understanding the relationship between same-race role-models and career and academic self-efficacy, two instruments were required to measure the constructs of career and academic self-efficacy. Career and academic self-efficacy is defined as a person's belief in his or her ability to follow an academic path through to a career. Participants completed the Career and Academic Self-Efficacy Scale (CASES; Brock, in revision; see Appendix A), which measures participants' beliefs in their ability to follow an academic/career path. 
The CASES was developed through a validation study establishing the psychometric properties of the scale; properties of reliability and validity were established through the evaluation of 310 participant responses. In order to create the CASES, the development of items in the scale was largely based on the format of the College Self-Efficacy Scale (Solberg, Villareal, \& Kennel, 1993), which was designed to measure students' self-efficacy with the process of adjusting to college life. Five experts in the field of academic and career self-efficacy were solicited for feedback on the possible instrument items. These experts were chosen based on their experience within the fields of education and social or vocational psychology, as well as their past publications on the construct of self-efficacy. From the expert responses, a pool of 30 possible items was created. Items were prefaced with the following question: "How confident are you in your ability to complete the following task?" Responses were rated on an eight-point Likert-type scale from "totally confident" (7) to "not at all confident" (0). A high score on the CASES indicates high career and academic self-efficacy, while a low score indicates low career and academic self-efficacy.

An exploratory factor analysis with varimax rotation was performed in order to identify key components of the CASES (Brock, in revision). This analysis also helped to identify items to be removed from the final item pool. Five major components were identified with eigenvalues above 1.0. These five components were rotated in a component matrix. Only 25 of the original 30 items loaded at greater than .50. Analysis of these 25 items revealed a Cronbach's Alpha coefficient of .935 , indicating possible redundancy of items. To achieve optimal internal consistency and scale length, 10 items were chosen for removal based on redundancy of item themes. Among the 15 remaining items, three major components emerged, accounting for $66.02 \%$ of the variance. The three components, with multiple items loading above .50 were 
labeled as the Career Preparation, Communication, and Degree Attainment Self-efficacy subscales Cronbach's Alpha for the subscales ranged from .78 to .91. The alpha coefficient for the full 15-item scale was calculated at .90 .

Convergent validity was established by comparing responses to the CASES with participant responses to the College Self-Efficacy Scale. The CASES had a moderately strong correlation to the College Self-Efficacy Scale $(r=.71, p<.01)$. Cronbach's alpha for the CASES was calculated at .90. Cronbach's alpha for the Career Preparation, Communication, and Degree Attainment Self-efficacy subscales were .91, .84, and .78, respectively. Moderate correlations were found between Career Preparation and Communication $(.52, p<.01)$ and between Career Preparation and Degree Attainment (.53, $p<.01)$. The Communication subscale was moderately correlated with Degree Attainment $(.35, p<.01)$.

Demographics. Participants also completed a demographic form that gathered information about socioeconomic status, education, gender, age, and number of same-race rolemodels. For the purpose of this study, a role-model was defined as any same-race professional with a college education. Although it is understood that role-models can be of any race and have varying levels of education, for the purpose of this study, this particular model is isolated in order to determine the possible influence that exposure to college-educated role-models may have on African American students' beliefs in their ability to follow academic and career paths that require higher education. The items related to role-models asked participants to identify the number of college graduates in their immediate family and extended family. These responses are indicated as "family role-models." The number of same-race teachers they had in grades $\mathrm{K}-12$ is listed as "teacher role-models." Both family and teacher role-models are coded as discrete variables. 


\section{Procedures}

All instruments were administered by the primary investigator in person, via classroom visits, and data were collected using paper and pencil surveys. Participants were asked to complete the College Self-Efficacy Scale (Solberg, 1993), the Career and Academic SelfEfficacy Scale (Brock, in revision), and the demographic form (Appendices A, B, and C, respectively). Participant data were kept in a locked file cabinet to insure privacy, and no identifying data were collected in order to increase confidentiality. All participants were informed of their right to discontinue participation in the study at any time without consequences.

In the pilot study, participants were solicited by contacting undergraduate professors through email, word of mouth, and social media, in order to request that the researcher be permitted to collect data in their classrooms. When professors identified their classroom as one in which the researcher was permitted to collect data, he visited their classrooms for the purpose of soliciting participants and administering the instruments. After reading a recruiting letter that discussed voluntary participation, anonymity, and confidentiality parameters to the students, the researcher administered the instruments, in group format, to any and all volunteers from the classrooms. Although any student that volunteered for the study was administered the instruments, only participants over 18 years old that self-identified as African American or partially African American were included in the current study.

\section{Analysis}

A hierarchical multiple regression was appropriate in this study due to its ability to create predictive equations. The goal of this study was to provide an understanding of the relationship that the number of same-race role-models has with career and academic self-efficacy. The 
numbers of teacher role-models and family role-models were used as predictor variables. Gender was used as a control variable. Career and academic self-efficacy was the criterion variable. Previous research has often studied the genders separately (Flores \& O’Brien, 2002; Hackett \& Betz, 1981; Hackett \& Byars, 1996). However, using gender as a control variable in the regression analysis allowed for the understanding of the impact of role-models when gender was accounted for.

The multiple regression analysis tested the following equation: $Y=a_{0}+b_{1} X_{1}+b_{2} X_{2}+$ $\mathrm{b}_{3} \mathrm{X}_{3}+\mathrm{e}$, where $\mathrm{Y}=$ self-efficacy scores, $\mathrm{X}_{1}=$ gender, $\mathrm{X}_{2}=$ family role-models, and $\mathrm{X}_{3}=$ teacher role-models. The multiple regression analysis allows for the understanding of the unique variance in self-efficacy scores that is accounted for by each of the predictor variables. Although these variables have previously been linked to student performance (Dixon-Román, Everson, \& McArdle, 2013; Linnehan, 2001; Santos \& Reigadas, 2000; Thile, 1995), the potential link to self-efficacy beliefs is not yet understood. The current study offers a unique view of the way Black students form their self-efficacy about their ability to follow career paths. 


\section{Chapter 3: Results}

The purpose of the current study was to explore the predictive relationship between the number of same-race role-models and career and academic self-efficacy among African American college students. Specifically, this study was designed to test two research questions:

- Does the total number of same-race role-models experienced in childhood have a significant positive correlation with the career and academic self-efficacy beliefs of African American college students?

- Does the number of African American teachers in a student's life account for a significant proportion of variance in career and academic self-efficacy beliefs when controlling for number of college-educated family role-models?

\section{Descriptive Statistics}

For the 87 participants, career and academic self-efficacy scores were assessed using the Career and Academic Self-Efficacy Scale (CASES; Brock, in revision). Cronbach's alpha was calculated at .91 for this scale with the current sample. The mean CASES score was calculated at $72.49(\mathrm{SD}=12.45)$ out of a possible total score of 105 . The number of same-race role-models was assessed using a demographic form. Participants indicated a mean of 6.95 family rolemodels with college degrees $(\mathrm{SD}=7.96)$, and participants reported a mean of $4.64(\mathrm{SD}=5.92)$ same-race teacher role-models.

In order to test for issues of collinearity, a Pearson correlation was used to measure the relationship between family role-models and teacher role-models. Because there was no significant correlation between these two variables $(r=.07, p=.52)$, it was believed that collinearity is, at most, a minor nuisance (Field, 2009). Homoscedasticity is the assumption that the variance of the residuals is constant at every level (Field, 2009). This was determined by 
testing a fit line through a scatterplot of the residuals of a regression model using total rolemodels as the predictor variable and CASES scores as the outcome variable. A flat fit line indicated that there was a presence of homoscedasticity. A Durbin-Watson test of this regression was used to detect independence of errors. According to Field, values less than 1 or greater than 3 on a Durbin-Watson test are cause for concern. A value of 2.19 on this test indicated no significant correlation between residuals.

A Shapiro Wilks test was used to test normality of distribution of the residuals from the regression analysis (Field, 2009). Non-normality was found to be statistically significant, indicating that the residuals of the regression analysis did not follow a normal distribution. A normal distribution of residuals indicates that the difference between the observed data and the model are close to zero and that differences much greater than zero only occur occasionally. A histogram and Q-Plot analysis of the standardized residuals revealed two significant outliers. The median standardized residual was $.11(\mathrm{SD}=.99)$. Outlier standard residuals were -4.05 and -4.40 , more than four standard deviations from the mean. Removal of these outliers resulted in a normal distribution of residuals on the resulting regression analysis. All subsequent analyses were done after the removal of these two outliers from the data set.

\section{Analysis of Hypotheses}

Two multiple regression analyses were used to test the predictive relationship of the number of role-models and career and self-efficacy beliefs. In order to test the impact of gender on self-efficacy scores, gender was entered into the stepwise regression as a control variable, while number of same-race teacher role-models and family role-models were entered as predictor variables. Career and academic self-efficacy was the outcome variable. To establish that gender acts as a moderator in the relationship between role-models and career and academic self- 
efficacy, gender would have to significantly add to the prediction of CASES scores. Thus, gender was entered into Step One of the regression to determine the predictive ability of the other predictor variables over and above the control variable. At this step, gender was not found to be significantly predictive of self-efficacy scores $(\beta=-.01, p=.916)$. Step Two of this analysis added family role-models and teacher role-models to the regression model. Neither family role-models $(\beta=-.17, p=.45)$ nor teacher role-models $(\beta=.10, p=.39)$ were predictive of self-efficacy beliefs after controlling for gender. Table 1 illustrates results of this regression. Because gender was not predictive of CASES scores, gender was excluded as a variable in subsequent analyses.

Table 1.

Regression Analysis Predicting Self-Efficacy

\begin{tabular}{|c|c|c|c|c|c|c|c|}
\hline \multirow[b]{2}{*}{ Variable } & \multicolumn{3}{|c|}{ Step 1} & \multicolumn{4}{|c|}{ Step 2} \\
\hline & $B$ & $S E B$ & $\beta$ & & $B$ & $S E B$ & $\beta$ \\
\hline Gender & -.29 & 2.74 & -.01 & & -.20 & 2.77 & .00 \\
\hline Family Role-Models & -- & -- & -- & & -.17 & .22 & -.09 \\
\hline Teachers Role-Models & & -- & -- & -- & .20 & .23 & .10 \\
\hline $\mathrm{R}^{2}$ & & .00 & & & & .01 & \\
\hline $\mathrm{F}$ & & .01 & & & & .57 & \\
\hline$d f$ & & 1.0 & & & & 2.0 & \\
\hline
\end{tabular}

Hypothesis 1. Hypothesis 1 proposed that the total number of same-race role-models would significantly predict career and academic self-efficacy scores. After removal of two outliers, the mean number of total same-race role-models was $11.65(\mathrm{SD}=10.35)$. CASES 
scores had a mean and standard deviation of 73.75 and 9.43 , respectively. A forced entry linear regression analysis was used to test this hypothesis. Results of the regression analysis were unable to reject the null hypothesis, as the total number of role-models was not predictive of scores on the CASES $(\beta=.05, p=.64)$.

Hypothesis 2. Hypothesis 2 proposed that the number of African American teachers would provide unique variance in CASES scores when controlling for family role-models. Among the 85 remaining participants, the mean number of same-race teachers was $4.71(\mathrm{SD}=$ 5.96). A hierarchical regression analysis was used to test the predictive value of teacher rolemodels after controlling for the impact of family role-models. Once again, the null hypothesis was not rejected, as no significant variance was accounted for by teacher role-models after controlling for family role-models $(\beta=.02, p=.87)$ (See Table 3).

These results suggest that the number of same-race role-models experienced by African American students does not significantly predict the career and academic self-efficacy beliefs of those students. When considered separately, the number of African American teacher rolemodels experienced by an African American student had no predictive value with respect to selfefficacy beliefs among African American college students. Although these findings are not encouraging for the many mentoring and role-model-based programs that exist within education programs for African American students, this information may yet prove fruitful for advocates of African American student needs. 
Table 2.

Hypothesis 2. Unique Predictive Value of Teacher Role-models

\begin{tabular}{|c|c|c|c|c|c|c|c|}
\hline \multirow[b]{2}{*}{ Variable } & \multicolumn{3}{|c|}{ Step 1} & \multicolumn{4}{|c|}{ Step 2} \\
\hline & $B$ & $S E B$ & $\beta$ & & $B$ & $S E B$ & $\beta$ \\
\hline Family Role-Models & .06 & .13 & .05 & & .06 & .13 & .05 \\
\hline Teachers Role-Models & & -- & -- & -- & .03 & .18 & .02 \\
\hline $\mathrm{R}^{2}$ & & .00 & & & & .01 & \\
\hline $\mathrm{F}$ & & .21 & & & & .03 & \\
\hline df1 & & 1.0 & & & & 1.0 & \\
\hline
\end{tabular}




\section{Chapter 4: Discussion}

The current study tested the relationship between same-race role-models and career and academic self-efficacy beliefs among African American college students. Two hypotheses were tested. First, it was hypothesized that the total number of same-race role-models experienced in childhood would have a significant positive correlation with the career and academic selfefficacy beliefs of African American college students. Results of this study did not support this hypothesis, as there was no significant predictive relationship between the total number of rolemodels and the self-efficacy beliefs of students. It was also hypothesized that the number of African American teachers in an African American student's life would account for a significant proportion of variance in career and academic self-efficacy beliefs after controlling for family role-models. This hypothesis also was not supported. When controlling for the number of family role-models with a college education, no significant variance in self-efficacy scores was accounted for by the number of same-race teacher role-models. These findings contradict previous research on role-modeling that suggests a positive impact of role-modeling on outcomes related to self-efficacy (Credle \& Dean, 1991; Henry, Bardo, \& Henry, 1992). This study was the first, however, to examine the direct impact that the number of role-models experienced would have on the self-efficacy beliefs of students.

This study, although unable to support the hypothesis that the number of same-race rolemodels would predict career and academic self-efficacy scores among African American students, offers support for previous research (Ainsworth, 2010) that suggests race is not a significant factor in role-modeling. The current findings add to the conversation about same-race role-modeling in that they add self-efficacy to the list of constructs that appear to be unaffected by race. 
The current study was successful in providing a preliminary answer to a question that has long been raised within research on African American students. The broad question of the impact of an increase in African American role-models is one that has been posed since desegregation (Epstein, 2005; Oakley \& Logan, 2009). The current study calls into question the idea that this increase will improve self-efficacy beliefs among African American students. This conclusion is important in that it provides a starting point for a body of research aimed at answering the broader question: How do we improve the academic performance of African American students? By examining the strength of the relationship between role-models and selfefficacy beliefs, the field is now better equipped to continue the search for what benefit an increase in role-models may have.

It is important to note that, although no significant predictive value was found in an increase in same-race role-models, several possible explanations for this result exist. It is possible that measures of concrete academic performance, such as SAT scores, grade point average, attendance, or graduation rates may have yielded stronger correlations to same-race role-models, despite the apparent lack of impact on self-efficacy beliefs. It is also possible that the way in which role-models were defined and measured creates an inherent problem. College students were asked to count the number of same-race teachers and family role-models they experienced throughout childhood. Participants were not asked to quantify the amount of time spent with these role-models or the perceived impact that these role-models may have had on students' lives. It may be helpful to quantify the amount of interaction students have with these role-models as a moderator variable in the relationship between role-models and self-efficacy beliefs. 
Yet another explanation worth examining, in future research, is that of the impact of racial identity. For the purpose of the current study, I chose not to measure the impact of racial identity development on the relationship between African American students and same-race rolemodels. However, it stands to reason that this construct may be a more significant moderator variable than was accounted for in this study. Bandura (1986) suggested that an effective model is one with whom the viewer can relate. It is possible that the degree to which African American students relate to same-race role-models is significantly impacted by the racial identity development of the student.

Several scholars (Cross, 1991; Helms, 1991; Sellers, Smith, Shelton, Rowley, \& Chavous, 1998) have suggested that racial identity plays an important role in the degree to which an African American person identifies with people and things associated with that group. With this in mind, it is possible that an African American student with strong African American racial identity would more strongly identify with a role-model that is African American. It is also possible, however, that students with weaker African American racial identity would not identify as strongly with African American role-models. The degree to which a student identifies with a role-model would be an important factor in measuring the impact of the relationship between the role-model and the student. Thus, it may be important to study the strength of racial identity as a moderator variable in a study of African American students' career and academic self-efficacy beliefs.

In the current study, students were from predominantly white institutions (PWI). A sample of students from HBCUs may yield different results. At HBCUs, African American students have essentially chosen to cultivate relationships with same-race peers and faculty. It is possible that these students have stronger African American racial identity and therefore more 
strongly identify with African American role-models. A study that uses students from both PWIs and HBCUs may allow for a comparison of the two groups of students with respect to racial identity and self-efficacy beliefs.

Still, assuming that the racial identity of the students is not an issue, the current study may best be explained through acceptance of the findings. According to the study, the number of same-race role-models experienced by African American students appears to have no significant relationship to their self-efficacy beliefs once the students are in college. In attempting to understand the relationship between role-modeling and self-efficacy beliefs among students, it may be more beneficial to measure the quality of the role-modeling than the quantity. Measures of the strength of any role-modeling relationship, such as number of interactions, perceived quality of relationship, and other variables, may be more important than the sheer number of role-models present in a student's life. In this respect, the current study provides valuable information in the ongoing pursuit of solutions to the challenges facing educators of African American students. In answering the current research questions, this study provides a rationale for future research on the subject.

\section{Limitations}

There are some obvious limitations to this study. The use of data from a previous study limited the freedom of the researcher to define variables of interest. Although some of the information gathered in the validation study was conceptually useful, the methodology of that study rendered some of the data unusable. For example, although socioeconomic status may have been a variable worth including in the current study, the self-report measure of family socioeconomic status (SES) was not sufficiently variable in the validation study and was therefore omitted in the current study. Roughly $50 \%$ of participants indicated middle-class 
status. Middle class and lower middle class accounted for roughly $77 \%$ of participant responses. Although it is possible that a large proportion of the students in this study came from middleclass families, the lack of variability limited the amount of impact that the variable had on the regression analysis. A more heterogeneous sample, with respect to SES, may have allowed for more impact from SES. A study that included both students and non-students may have allowed for this more heterogeneous sample, as it is likely that college students have at least the means to attend school. An exclusively college student sample excludes anyone who did not have either the means or the self-efficacy beliefs to enroll in college. This exclusion may have a significant impact on the results of this type of study.

The self-report method of measuring number of role-models may also have been problematic in the current study, as I was left to rely on the accurate reports of college students about the number of same-race teachers and family role-models they had encountered throughout their childhood. Although self-report surveys can provide convenience for researchers, the data is often prone to problems, as this data collection method is susceptible to influence from participants' motivation to report inaccurately (Robins \& John, 1997). Among the issues that self-report data is prone to, self-deception, faulty memory, and the desire to seek consistency may be of particular concern in the current study. As Robins and John pointed out, even when participants make efforts to be truthful and accurate, their reports may have little to do with reality. Future research using data from schools or the department of education may prove more fruitful. Using grade point averages, graduation rates, and attendance records provided directly by the schools would eliminate errors in student self-reporting and may allow for more accurate study of the impact same-race role-models may have on academic outcomes. 
It is also difficult to measure the impact that college has had on the sampled population. The current study measured the number of role-models experienced during the years before college. However, by measuring the self-efficacy beliefs of students who are currently in college, this study does not take into consideration the impact that the college experience may have had on their self-efficacy beliefs. It is possible that the college years, and same race rolemodels that these students have encountered, may act as a moderator variable, strengthening or weakening the relationship between previous role-models and the self-efficacy beliefs of the participants. A study that samples high school students may eliminate this moderating factor.

Another possible moderator variable may be the amount of time spent with role-models. As previously stated, the current study quantifies the number of role-models experienced in a student's life while not considering the amount of time spent with these role-models. Especially with respect to family role-models, there may be a significant difference in the impact of a distant relative when compared to an older sibling or parent with whom a student spends significant amounts of time. With respect to teacher role-models, there may also be a difference between a teacher with whom a student has a meaningful relationship and one with whom the student has little interaction. A study that allows for the impact that time and strength of relationship may have as a moderator variable in the relationship between role-models and selfefficacy beliefs would perhaps yield different results.

The purpose of the current study was to attempt to establish a correlation between number of same-race role-models and student self-efficacy. Future researchers are left to speculate about the true nature of the relationship between the number of role-models experienced by a student and their self-efficacy beliefs. The nuances of the role-modeling relationship and its impact on self-efficacy are clearly complex. A qualitative study of this 
relationship may be helpful in unpacking what aspects of the role-modeling relationship are most impactful to students. The current study fell short of providing a clear picture of the impact that same-race role-models have on African American students. A qualitative study, however, may allow researchers to understand, based on the lived experiences of both students and teachers, what is most impactful about the relationship between African American students and teachers. Where the current study assumed that the strength of this relationship is in its quantitative impact on self-efficacy, a qualitative study would allow for the emergence of new concepts in the understanding of this relationship based on experiential data. This may be helpful in directing future research.

\section{Strengths}

One of the strengths of this study is that it serves to fill in holes that exist in the literature on African American student self-efficacy. Many of the studies of this nature are performed in settings where African American students are abundant and even in the majority (Kafele, 2012; Lease, 2006; Witherspoon \& Speight, 2009). These settings, however, may not be representative of African American students outside of these settings. The current study was able to offer a relatively rare look at African American college students outside of the HBCUs in which they are often studied. Continued research on African American students in these more diverse areas will provide valuable insight into the unique experiences of those African American students who go to school at predominantly White institutions.

Another strength of this study is that it begins to bridge the gap between literature on same-race role-models for African Americans and that of self-efficacy in African American students. Writers within education and psychology have long addressed minority performance, persistence, and self-efficacy through research on test taking, achievement gaps, and the like 
(Jencks \& Phillips, 1999; Paik \& Walberg, 2007). Much of that literature, however, focuses on explanation of the differences African American students display when compared to their Caucasian counterparts rather than positing possible solutions to underachievement issues in African American students. Although role-modeling research is not new within the field of minority education, such a direct correlation between number of adult role-models and academic self-efficacy has not been widely explored. The theoretical and empirical foundation of selfefficacy theory is strong. A clear link has been made in psychological literature between student self-efficacy and academic outcomes (Lent, Brown, \& Larkin, 1984; 1986; Multon, Brown, \& Lent, 1991). The current study adds to that body of knowledge in that it continues the conversation within the field about solutions to the problems that have traditionally existed in educating African American students. The current study offers an answer to one of the many questions that exist about the African American student population, as well as offering a new avenue of research and intervention within the fields of psychology and education.

\section{Future Directions}

As previously stated, future qualitative research is needed in order to determine the most salient aspects of the relationship between Black students and their same-race role-models. Qualitative research, perhaps from a Grounded Theory perspective, would help direct future study of this topic by allowing the theoretical perspective to be driven by the experiences of those being studied (Merriam, 2009).

In order to further assess the impact of same-race role-models on self-efficacy among African American students, future researchers may also want to conduct research within a controlled environment. An experiment performed with a treatment and control group, with an intervention designed to increase student interaction with role-models, would allow researchers 
to assess the impact that role-modeling may have on self-efficacy and other variables, while controlling for confounding variables. This experimental design may be the only way to truly understand the impact that same-race role-models have on self-efficacy among African American students.

\section{Contribution to the Field}

The current study has undeniable connections to the field of counseling psychology. In studying the impact of self-efficacy on African American students, this study relies on and expands upon the work of a leading psychologist, Albert Bandura. Bandura's (1986) pioneering theories of social learning and self-efficacy have been used to understand the ways in which human beings function within any number of settings, from education and learning to medicine and healing behavior. The current study adds to this body of work in that it looks at the intricacies of social learning within a population that is desperately in need of increased research attention.

This study also speaks to one of the emerging movements in counseling psychology in that, at its core, this study is about social justice (Fouad et al., 2004; Toporek, Gerstein, Fouad, Roysircar, \& Israel, 2006; Vera \& Speight, 2003). The underlying basis for this study is to identify and justify useful interventions that would improve the lives and performance of African American students, and ultimately, African American employees. Understanding the impact of increased role-models, especially within schools, may one day help drive policy decisions in the hiring and retention of African American teachers. Although this study failed to correlation between self-efficacy beliefs and the number of same-race teachers in a student's life, it is likely that future research will uncover what benefits increased role-models would provide to African American students. Those future findings will lend weight to arguments for changes in ways in 
which America educates this population. This impact on the overall life and wellbeing of an underserved population is part of a tradition of advocacy within counseling psychology.

Also at the heart of this study is a contribution to vocational psychology, which is central to the field of counseling psychology (Munley, Duncan, McDonnell, \& Sauer, 2004). Since its inception, counseling psychology has been rooted in the work of Frank Parsons (1909) and others who have treated career choice as an important domain in the consideration of counseling and guidance of human subjects. Notable contributors have added to the understanding of career choice and vocational psychology throughout the history of counseling psychology (Holland, 1959; Super, 1953; Wingfield \& Eccles, 2002). The current study expounds upon the work of Lent, Brown, and Hackett (1994) in their exploration of the interaction between self-efficacy and career choices. Their Social Cognitive Career Theory has been the basis for the study of career choice among students (Solberg et al., 2003). The current study expands this research by exploring these concepts among African American students.

There are several implications of this study within the field of education. A greater understanding of the self-efficacy beliefs of African American students has undeniable merit. Adding to the body of knowledge about this subject is only one of the contributions this study brings to the field. By increasing understanding of the impact of same-race role-modeling, this study adds to a growing body of research about the needs and behaviors of African American students. Increased knowledge in this area will provide insight for school counselors hoping to provide career guidance to these students.

Perhaps the most important implication of this study is in the social psychology imbedded within it. Although the immediate impact of this research is within the field of education, successful discoveries in self-efficacy improvement for African American students 
have social and psychological implications that go far beyond the improvement of school performance. These advancements could begin to address the question first posed by W.E.B. Dubois (1903) and studied by many researchers on African American racial identity over the years (Cross, 1991; Helms, 1991; Sellers, Smith, Shelton, Rowley, \& Chavous, 1998) - the question of what it means to be African American. Systematic improvement in the performance and self-efficacy beliefs of African American young people could erode the evidence that has been used to perpetuate an implied inferiority among them in the United States. At the core of any research on African American student achievement gaps, differential crime rates among racial groups, or occupational and socioeconomic disparities between African Americans and Caucasians is the fundamental question of how to erase the obstacles faced by a race of people plagued by hurdles and handicaps since arrival in this country. Marked improvement in the academic and career self-efficacy beliefs of young African Americans could help overcome one of those obstacles.

\section{Conclusion}

This study examines the relationship between the number of same-race role-models and the career and academic self-efficacy of African American college students. The study contributes to the knowledge base about African American student self-efficacy, social learning, and role-modeling. It provides a catalyst for future research on role-modeling and self-efficacy within the African American population. The results of this study provide useful information from which schools, school psychologists, and counseling psychologists can build for improvement of the system of educating African American students. 


\section{References}

Ainsworth, J. W. (2010). Does the Race of Neighborhood Role-models Matter? Collective Socialization Effects on Educational Achievement. Urban Education, 45(4), 401-423.

Ali, S., \& Saunders, J. (2009). The career aspirations of rural Appalachian high school students. Journal of Career Assessment, 17(2), 172-188.

Aud, S., Hussar, W., Johnson, F., Kena, G., Roth, E., Manning, E., Wang, X., \& Zhang, J. (2012). The Condition of Education 2012 (NCES 2012-045). U.S. Department of Education, National Center for Education Statistics. Washington, DC.

Aud, S., Fox, M., and Kewal-Ramani, A. (2010). Status and Trends in the Education of Racialand Ethnic Groups (NCES 2010-015). U.S. Department of Education, National Center for Education Statistics. Washington, DC: U.S. Government Printing Office.

Bandura, A. (1986). Social Foundations of Thought and Action: A social Cognitive Theory. Englewood Cliffs, NJ US: Prentice-Hall, Inc.

Bandura, A., Adams, N. E., Hardy, A. B., \& Howells, G. N. (1980). Tests of the generality of self-efficacy theory. Cognitive Therapy And Research, 4(1), 39-66.

Bandura, A., Barbaranelli, C., Caprara, G., \& Pastorelli, C. (2001). Selfefficacy beliefs as shapers of children's aspirations and career trajectories. Child Development, 72(1), 187-206.

Bandura, A., Reese, L., \& Adams, N. E. (1982). Microanalysis of action and fear arousal as a function of differential levels of perceived self-efficacy. Journal of Personality and Social Psychology, 43(1), 5-21.

Belgrave, F.Z., \& Allison, K.W. (2010). Introduction to African American Psychology. African American Psychology: from Africa to America (2nd ed).Thousands Oak California. 1-25. 
Belgrave, F. Z., Townsend, T. G., Cherry, V. R., \& Cunningham, D. M. (1997). The influence of an Africentric worldview and demographic variables on drug knowledge, attitudes, and use among African American youth. Journal of Community Psychology, 25(5), 421-433.

Bem, S. L. (1974). The measurement of psychological androgyny. Journal of Consulting and Clinical Psychology, 42(2), 155-162.

Betz, N., \& Hackett, G., (1981). A self-efficacy approach to the career development of women. Journal of Vocational Behavior, 23, 329-345.

Betz, N., \& Hackett, G., (1983). The relationship of mathematics self-efficacy expectations to the selection of science based college majors. Journal of Vocational Behavior, 23, 329345.

Bullock-Yowell, E., Andrews, L., \& Buzzetta, M. E. (2011). Explaining career decision making self-efficacy: personality, cognitions, and cultural mistrust. Career Development Quarterly, 59(5), 400-411.

Byars-Winston, A., Estrada, Y., Howard, C., Davis, D., \& Zalapa, J. (2010). Influence of social cognitive and ethnic variables on academic goals of underrepresented students in science and engineering: A multiple-groups analysis. Journal of Counseling Psychology, 57(2), 205-218.

Credle, J., \& Dean, G. (1991). A comprehensive model for enhancing black student retention in higher education. Journal of Multicultural Counseling \& Development, 19(4), 158-165.

Cross, W. E. Jr. (1971). The Negro-to-Black conversion experience. Black World, 20 (9), 13-27.

Cross, W. (1991). Shades of black: Diversity in African-American identity. Philadelphia, PA US: Temple University Press.

Dee, T. (2005). A teacher like me: Does race, ethnicity or gender matter. 
American Economic Review, 95(2), 158-165.

Denson, C. D., \& Hill, R. B. (2010). Impact of an engineering mentorship program on AfricanAmerican male high school students' perceptions and self-efficacy. Journal of Industrial Teacher Education, 47(1), 99-127.

Dixon-Román, E. J., Everson, H. T., \& McArdle, J. J. (2013). Race, Poverty and SAT Scores: Modeling the Influences of Family Income on Black and White High School Students' SAT Performance. Teachers College Record, 115(4), 1-33.

DuBois, D., Holloway, B., Valentine, J., \& Cooper, H. (2002). Effectiveness of mentoring programs for youth: A meta-analytic review. American Journal of Community Psychology, 30(2), 157.

Durodoye, B., \& Bodley, G. (1997). Career development issues for ethnic minority college students. College Student Journal, 31(1), 27.

Edman, J. L., \& Brazil, B. (2009). Perceptions of campus climate, academic efficacy and academic success among community college students: an ethnic comparison. Social Psychology of Education, 12(3), 371-383.

Epstein, K. K. (2005). The Whitening of the American Teaching Force: A Problem of Recruitment or a Problem of Racism?. Social Justice, 32(3), 89-102.

Feistritzer, C.E. (2011). Profile of teachers in the U.S. National Center for Educational Information. Washington, D.C.

Field, A. P. (2009). Discovering statistics using SPSS : (and sex and drugs and rock ' $n$ ' roll). Los Angeles ; London : SAGE, c2009.

Flores, L., \& O'Brien, K. (2002). The career development of Mexican American 
adolescent women: A test of social cognitive career theory. Journal of Counseling Psychology, 49(1), 14-27.

Flores, L., \& Navarro, R., \& DeWitz, S., (2008). Mexican American high school students' postsecondary educational goals. Journal of Career Assessment, $16(4), 489-501$.

Fouad, N. A., McPherson, R., Gerstein, L., Blustein, D. L., Elman, N., Helledy, K. I., \& Metz, A. J. (2004). Houston, 2001: Context and legacy. Counseling Psychologist, 32, 15-77.

Fries-Britt, S. L., Rowan-Kenyon, H. T., Perna, L. W., Milem, J. F., \& Howard, D. (2011). Underrepresentation in the Academy and the Institutional Climate for Faculty Diversity. Journal of The Professoriate, 5(1), 1-34.

Gloria, A., \& Hird, J. (1999). Influences of ethnic and nonethnic variables on the career decisionmaking self-efficacy of college students. Career Development Quarterly, 48(2), 157.

Greene, B. A. (1990a). What has gone before: The legacy of racism and sexism in the lives of Black mothers and daughters. Women and Therapy, 9, 207-230.

Grier-Reed, T., \& Ganuza, Z. M. (2011). Constructivism and career decision self-efficacy for Asian Americans and African Americans. Journal of Counseling \& Development, 89(2), 200-205.

Grossman, J., Roffman, J., \& Rhodes, J. (2002). The rhetoric and reality of youth mentoring. New Directions for Youth Development, 2002(93), 9-20.

Gushue, G. V., \& Whitson, M. L. (2006). The relationship among support, ethnic identity, career decision self-efficacy, and outcome expectations in African American high school students: Applying social cognitive career theory. Journal of Career Development, 33(2), $112-124$. 
Hackett, G., \& Betz, N. (1981). A self-efficacy approach to the career development of women. Journal of Vocational Behavior, 16, 326-339.

Hackett, G., \& Byars, A. (1996). Social cognitive theory and the career development of African American women. Career Development Quarterly, 44(4), 322.

Helms, J. E. (1990). Black and White racial identity: Theory, research, and practice. New York, NY, England: Greenwood Press.

Helms, J., \& Carter, R. (1991). Relationships of white and black racial identity attitudes and demographic similarity to. Journal of Counseling Psychology, 38(4), 446.

Henry, P., Bardo, H., \& Henry, C. (1992). The effectiveness of career development seminars on African American premedical students: A program evaluation using the Medical Career Development Inventory. Journal of Multicultural Counseling \& Development, 20(3), 99-112.

Holland, J. L. (1959). A theory of vocational choice. Journal Of Counseling Psychology, 6(1), $35-45$.

Holland, J. L. (1997). Making Vocational Choices: A Theory of Vocational Personalities and Work Environments (3rd ed.). Odessa, FL US: Psychological Assessment Resources.

Holsendolph, E. (2007). Each one, teach one. Diverse: Issues in Higher Education, 24(9), 12-15.

Holt, L., Bry, B., \& Johnson, V. (2008). Enhancing school engagement in at-risk, urban minority adolescents through a school-based, adult mentoring intervention. Child \& Family Behavior Therapy, 30(4), 297-318. 
Hussar, W.J., and Bailey, T.M. (2013). Projections of Education Statistics to 2021 (NCES 2013 008). U.S. Department of Education, National Center for Education Statistics. Washington, DC: U.S. Government Printing Office.

Jencks, C., \& Phillips, M. (1999). The black-white test score gap. Current, (409), 9.

Karcher, M., Kuperminc, G., Portwood, S., Sipe, C., \& Taylor, A. (2006). Mentoring programs: A framework to inform program development, research, and evaluation. Journal of Community Psychology, 34(6), 709-725.

Kafele, B. K. (2012). Empowering Young Black Males. Educational Leadership, 70(2), 67-70.

Lease, S. H., (2006). Factors predictive of the range of occupations considered by African American juniors and seniors in high school. Journal of Career Development, 32(4) 333 350.

Lent, R., \& Brown, S. (1996). Social cognitive approach to career development: An overview. Career Development Quarterly, 44(4), 310.

Lent, R. W. \& Brown, S. D. (2006). On conceptualizing and assessing social cognitive constructs in career research: a measurement guide. Journal of career assessment, 14, $12-35$.

Lent, R. W., Brown, S. D., \& Hackett, G. (1994). Toward a unifying social cognitive theory of career and academic interest, choice, and performance. Journal of Vocational Behavior, $45,79-122$.

Lent, R. W., Brown, S. D., \& Larkin, K. C. (1984). Relation of self-efficacy expectations to academic achievement and persistence. Journal of Counseling Psychology, 31(3), 356362. 
Lent, R. W., Brown, S. D., \& Larkin, K. C. (1986). Self-efficacy in the prediction of academic performance and perceived career options. Journal of Counseling Psychology 33(3), 265-269.

Lent, R. W., Brown, S. D., Sheu, H., Schmidt, J., Brenner, B. R., Gloster, C. S., \& Lyons, H.(2005). Social cognitive predictors of academic interests and goals in engineering: utility for women and students at historically black universities. Journal of Counseling Psychology, 52(1), 84-92.

Linnehan, F. (2001). The relation of a work-based mentoring program to the academic performance and behavior of African American students. Journal of Vocational Behavior, 59(3), 310-25.

Liu, M., Hsieh, P., Cho, Y., \& Schallert, D. (2006). Middle school students' self-efficacy, attitudes, and achievement in a computer-enhanced problem-based learning environment. Journal of Interactive Learning Research, 17(3).

Liu, M., Williams, D., \& Pedersen, S. (2002). Alien rescue: A problem-based hypermedia learning environment for middle school science. Journal of Educational Technology Systems, 30(3), 255-270.

Lyons, J., \& Chesley, J. (2004). Fifty years after Brown: The benefits and tradeoffs for African American educators and students. Journal of Negro Education, 73(3), 298-313.

Madkins, T. C. (2011). The Black Teacher Shortage: A Literature Review of Historical and Contemporary Trends. Journal Of Negro Education, 80(3), 417-427.

Maylor, U. (2009). 'They do not relate to Black people like us': Black teachers as role-models for Black pupils. Journal of Education Policy, 24(1), 1-21. 
McNulty, C., \& Brown, M. (2009). Help wanted: Seeking the critical confluence of minorities in teaching. Childhood Education, 85(3), 179.

Merriam, S. B. (2009). Qualitative research: A guide to design and implementation. San Francisco, CA: Jossey-Bass.

Multon, K. D., Brown, S. D., \& Lent, R. W. (1991). Relation of self-efficacy beliefs to academic outcomes: A meta-analytic investigation. Journal Of Counseling Psychology, 38(1), 30-38.

Munley, P., Duncan, L., McDonnell, K., \& Sauer, E. (2004). Counseling psychology in the United States of America. Counseling Psychology Quarterly, 17(3), 247-271.

Niles, S. \& Harris-Bowlsbey, J. (2005). Understanding and applying emerging theories of career development. In S. Niles, \& J. Harris-Bowlsbey (Eds.), Career Development Interventions in the $21^{\text {st }}$ Century (pp. 85-116). Upper Sadle River, New Jersey: Pearson Merrill Prentice Hall.

Oakley, D., Stowell, J., \& Logan, J. R. (2009). The impact of desegregation on black teachers in the metropolis, 1970-2000. Ethnic \& Racial Studies, 32(9), 1576-1598.

Ogbu, J. U. (1991). Minority coping responses and school experience. Journal of Psychohistory, 18, 433-456.

Paik, S., \& Walberg, H. (2007). Narrowing the Achievement Gap strategies for Educating Latino, Black, and Asian students. New York, NY US: Springer Science + Business Media.

Pajares (2002). Overview of social cognitive theory and of self-efficacy. Retreived April 19, 2014, from http://www.emory.edu/EDUCATION/mfp/eff.html. 
Parham, T. A., \& Helms, J. E. (1985). Attitudes of racial identity and self-esteem of Black students: An exploratory investigation. Journal Of College Student Personnel, 26(2), 143-147.

Parsons, F. (1909). Choosing a vocation. Boston, MA: Houghton Mifflin.

Phinney, J. S. (1992). The multigroup ethnic identity measure: A new scale for use with diverse groups. Journal Of Adolescent Research, 7(2), 156-176.

Purkey, W., \& Novak, J. M. (1996). Inviting School Success: A Self-Concept Approach to Teaching, Learning, and Democratic Practice. Third Edition.

Quimby, J.L., Wolfson, J.L., \& Seyala N.D., (2007). Social cognitive predictors of African American adolescents' career interest. Journal of Career Development, 33(4). 376394.

Robins, R. W., \& John, O. P. (1997). The quest for self-insight: Theory and research on accuracy and bias in self-perception. In R. Hogan, J. A. Johnson, S. R. Briggs, R. Hogan, J. A. Johnson, S. R. Briggs (Eds.), Handbook of personality psychology (pp. 649-679). San Diego, CA, US: Academic Press.

Rowan-Kenyon, H. r., Swan, A. K., \& Creager, M. F. (2012). Social Cognitive Factors, Support, and Engagement: Early Adolescents' Math Interests as Precursors to Choice of Career. Career Development Quarterly, 60(1), 2-15.

Sánchez, V. A. (2015). Affirmative Action and Faculty in Higher Education. Vermont Connection, 3665-72.

Santos, S., \& Reigadas, E. (2000). Evaluation of a University Faculty Mentoring Program: Its Effect on Latino College Adjustment. 
Suarez-Balcazar, Y., Orellana-Damacela, L., Portillo, N., Rowan, J. M., \& Andrews-Guillen, C.(2003). Experiences of Differential Treatment among College Students of Color. Journal of Higher Education, 74(4), 428-44.

Sellers, R., Smith, M., Shelton, J., Rowley, S., \& Chavous, T. (1998). Multidimensional model of racial identity: A reconceptualization of African American racial identity. Personality \& Social Psychology Review (Lawrence Erlbaum Associates), 2(1), 18.

Shin, R. Q. (2011). The influence of Africentric values and neighborhood satisfaction on the academic self-efficacy of African American elementary school children. Journal of Multicultural Counseling and Development, 39(4), 218-228.

Snyder, T.D., \& Dillow, S.A., (2010). Digest of Educational Statistics 2009. Washington, DC: National Center for Educational Statistics.

Solberg, V., O'Brien, K., Villareal, P., Kennel, R., \& Davis, B. (1993). Self-Efficacy and Hispanic College Students: Validation of the College Self-Efficacy Instrument. Hispanic Journal of Behavioral Sciences, 15(1), 80-95.

Strayhorn, T. L. (2015). Factors Influencing Black Males' Preparation for College and Success in STEM Majors: A Mixed Methods Study. Western Journal Of Black Studies, $39(1), 45-63$.

Super, D. E. (1953). A theory of vocational development. American Psychologist, 8(5), 185-190.

Tang, M., Fouad, N., \& Smith, P. (1999). Asian Americans' career choices: A path model to examine factors influencing their career choices. Journal of Vocational Behavior, 54(1), $142-57$. 
Thile, E., \& Matt, G. (1995). The ethnic mentor undergraduate program: A brief description and preliminary findings. Journal of Multicultural Counseling \& Development, 23(2), 116126.

Toporek, R., Gerstein, L., Fouad, N., Roysircar, G., \& Israel, T. (Eds.). (2006). Handbookfor social justice in counseling psychology: Leader- ship, vision, and action. Thousand Oaks, CA: Sage.

U.S. Women's Bureau (1975). Handbook on Women Workers. Washington, D.C.: U.S.

Government Printing Office.

Usher, E. L., \& Pajares, F. (2006). Inviting confidence in school: Invitations as a critical source of the academic self-efficacy beliefs of entering middle school students. Journal of Invitational Theory and Practice, 12, 7-16.

Valiante, G., \& Pajares, F., (1999). The inviting/disinviting index: instrument validation and relation to motivation and achievement. Journal of Invitational Theory and Practice, $6(1), 28-47$

Vera, E. M., \& Speight, S. L. (2003). Multicultural competence, social justice, and counseling psychology: Expanding our roles. Counseling Psychologist, 31, 253-272.

Vogt, P., \& Haasdijk, E. (2010). Modeling Social Learning of Language and Skills. Artificial Life, 16(4), 289-309.

Wingfield A., \& Eccles J. S. (2002). Developing of Achievement Motivation. San Diego: Academic Press.

Witherspoon, K.M., \& Speight, S. L., (2009). An exploration of African Americans' interests and self-efficacy beliefs in traditional and nontraditional careers. Journal of Black Studies, 39(6), 888-904 
Zeldin, A. L., \& Pajares, F. (2000). Against the odds: Self-efficacy beliefs of women in mathematical, scientific, and technological careers. American Educational Research Journal, 37, 215-24. 


\author{
Appendix A: Demographic Form
}

Age:

Gender: $\mathrm{M}$ F

Race (circle): Black/African-American White Asian

Hispanic Native America Other:

Last Grade Completed: $9 \quad 10 \quad 11 \quad 12$ Freshman Sophomore Junior Senior Grad+

Family Socioeconomic Status:

Lower Class Lower Middle Class Middle Class Upper Middle Class Upper Class

How many college graduates are in your immediate family? (include parents, stepparents, siblings)

How many college graduates are in your extended family? (include parents, stepparents, siblings)

How many same race teachers did you have in K-8?

How many same race teachers did you have in high school? 


\section{Appendix B: College Self-Efficacy Scale}

This questionnaire seeks information regarding your degree of confidence in completing tasks associated with being at your college. You will be asked to respond to a series of statements by marking the number which best represents your present attitude or opinion. Remember this is not a test and there are no right or wrong answers. The answer categories range from:

0 - totally unconfident

1- very unconfident

2- unconfident

3- somewhat unconfident

4- undecided

5- somewhat confident

6- very confident

7- totally confident

Example:

You would mark (5) if you are somewhat confident with:

Finding the Union.

Using the scale provided please mark the number which best represents the degree to which you feel confident performing the following tasks.

1. Make new friends at college

2. Talk to your professor/instructor

3. Take good class notes

4. Divide chores with others you live with

5. Research a term paper

6. Join an intramural sports team

7. Understand your textbooks

8. Get a date when you want one

9. Ask a professor or instructor a question outside of class

10. Get along with others you live with

11. Write a course paper

12. Work on a group project

13. Socialize with others you live with

14. Do well on your exams

15. Talk with a school academic and support (e.g. advising) staff

16. Manage your time effectively

17. Use the Library

18. Join a student organization

19. Ask a question in class

20. Divide space in your residence (if applicable)

21. Participate in class discussions

22. Keep up to date with your school work 


\section{Appendix C: Career and Academic Self-Efficacy Scale}

This questionnaire seeks information regarding your degree of confidence in completing tasks associated with following your ideal or "dream" career path. You will be asked to respond to a series of statements by marking the number which best represents your present attitude or opinion. Remember this is not a test and there are no right or wrong answers. The answer categories range from:

1- totally unsure

2- very unsure

3- unsure

4- somewhat unsure

5- somewhat sure

6- very sure

7- totally sure

Example:

You would mark (4) if you are somewhat confident with: Researching a term paper.

Using the scale provided please mark the number that best represents the degree to which you feel confident performing the following tasks.

1. Earn a degree in your chosen career field

2. Talk to your professor/instructor

3. Take good class notes

4. Perform the daily tasks in your chosen career field

5. Research a term paper

6. Get a job in your chosen career field

7. Understand your textbooks

8. Graduate from college

9. Ask a professor or instructor a question outside of class

10. Earn an advanced degree in your chosen field if necessary

11 . Identify career options

12. Attend a career fair

13. Do well on a job interview

14. Do well on your exams

15. Talk with a school academic and support (e.g. advising) staff

16. Manage your time effectively

17. Use the Library

18. Create an effective resume 
19. Identify mentors or role-models within your chosen career path

20. Ask a question in class

21. Talk to your boss in your chosen career

22. Maintain a career in your chosen field

23. Participate in class discussions

24. Keep up to date with your school work

25. Search for jobs within your chosen field

26. Select a career that best matches your interests and aptitudes.

27. Identify school and community resources available to help achieve my career goal(s).

28. $\overline{\text { Research }}$ the interests, knowledge, skills, and abilities needed in an occupation.

29. Identify an appropriate apprenticeship or internship experience

30. Keep up to date with current trends within your chosen field 